University of Louisville

ThinkIR: The University of Louisville's Institutional Repository

Electronic Theses and Dissertations

6-2007

\title{
A modified greedy algorithm for the task assignment problem.
}

Allison M. Douglas

University of Louisville

Follow this and additional works at: https://ir.library.louisville.edu/etd

\section{Recommended Citation}

Douglas, Allison M., "A modified greedy algorithm for the task assignment problem." (2007). Electronic Theses and Dissertations. Paper 369.

https://doi.org/10.18297/etd/369

This Master's Thesis is brought to you for free and open access by ThinkIR: The University of Louisville's Institutional Repository. It has been accepted for inclusion in Electronic Theses and Dissertations by an authorized administrator of ThinkIR: The University of Louisville's Institutional Repository. This title appears here courtesy of the author, who has retained all other copyrights. For more information, please contact thinkir@louisville.edu. 
By

Allison M. Douglas

B.S., University of Louisville, 2006

\author{
A Thesis \\ Submitted to the Faculty of the \\ University of Louisville \\ J.B. Speed School of Engineering \\ in Partial Fulfillment of the Requirements \\ for the Professional Degree
}

\title{
MASTER OF ENGINEERING
}

Department of Industrial Engineering

June 2007 

A MODIFIED GREEDY ALGORITHM FOR THE TASK ASSIGNMENT PROBLEM

Submitted by:

Allison M. Douglas

(Date)

By the Following Reading and Examination Committee:

Dr. Gail W. Depuy, Thesis Director

Dr. John S. Usher

Dr. Eric C Rouchka 


\section{ACKNOWLEDGEMENTS}

Thank you to Marla Fredrick, Barbara Strahley and Randy Walker at Crane Division, Naval Surface Warfare Center (NSWC) for their assistance providing real-world information regarding the task allocation problem and the sample data sets used for analysis in this study.

I would also like to acknowledge the members of my thesis committee, Dr. J. S.

Usher and Dr. E. C. Rouchka for their contribution. A special thank you to my thesis

advisor, Dr. G. W. Depuy for her guidance. 


\begin{abstract}
Assigning workers to tasks in an efficient and cost effective manner is a problem that nearly every company faces. This task assignment problem can be very time consuming to solve optimally. This difficulty increases as problem size increases. Most companies are large enough that it isn't feasible to find an optimal assignment; therefore a good heuristic method is needed. This project involved creating a new heuristic to solve this problem by combining the Greedy Algorithm with the Meta-RaPS method. The Greedy Algorithm is a near-sighted assignment procedure that chooses the best assignment at each step until a full solution is found. Although the Greedy Algorithm finds a good solution for small to medium sized problems, introducing randomness using the meta-heuristic Meta-RaPS results in a better solution. The new heuristic runs 5000 iterations and reports the best solution. The final Excel ${ }^{\circledR}$ VBA program solves a small sized problem in less than one minute, and is within $10 \%$ of the optimal solution, making it a good alternative to time consuming manual assignments. Although larger, more realistic problems will take longer to solve, good solutions will be available in a fraction of the time compared to solving them optimally.
\end{abstract}




\section{TABLE OF CONTENTS}

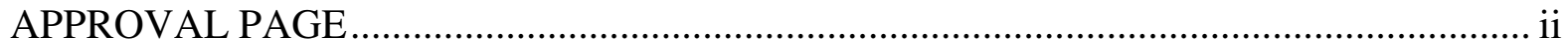

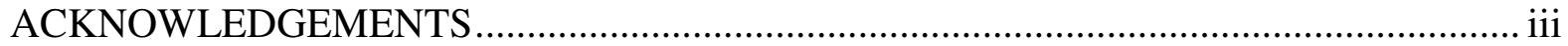

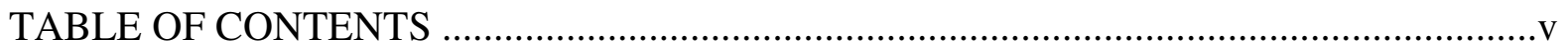

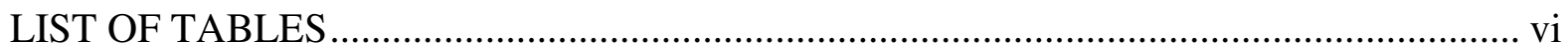

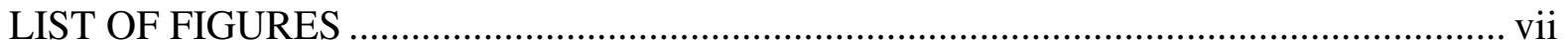

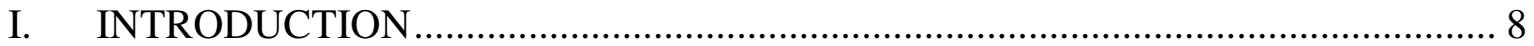

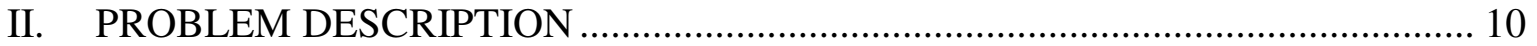

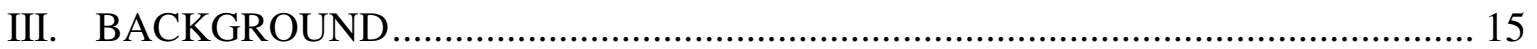

IV. WORKERSKILLS ASSIGNMENT PROCEDURE........................................... 17

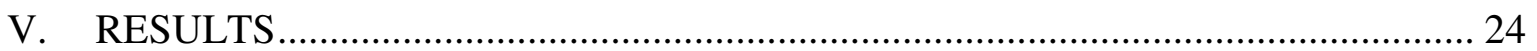

VI. CONCLUSIONS AND RECOMMENDATIONS .............................................. 32

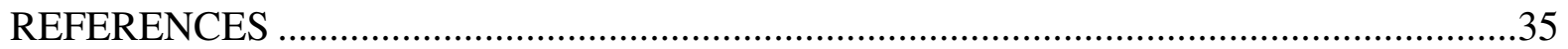

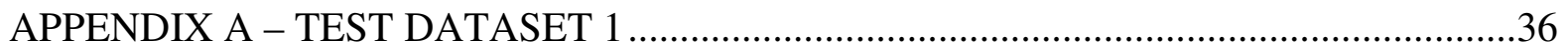

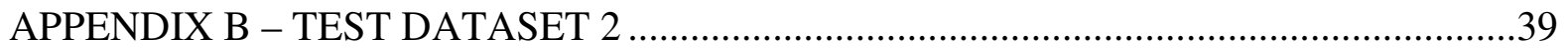

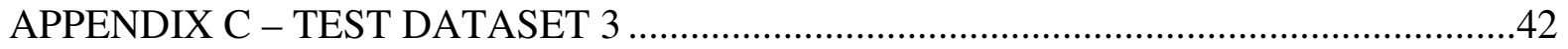

APPENDIX D - CODE FOR CREATING INPUT SHEET ….....................................45

APPENDIX E - SCREENSHOTS OF INPUT SHEET …............................................48

APPENDIX F - CODE FOR MODIFIED GREEDY ALGORITHM .................................51

APPENDIX G - SCREENSHOTS OF RESULTS AND OUTPUT SHEETS .....................63

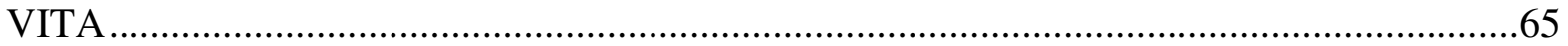




\section{LIST OF TABLES}

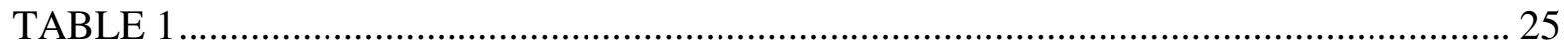

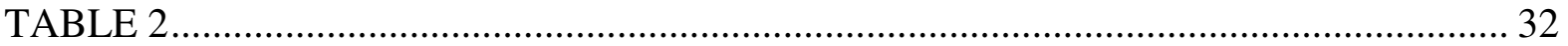

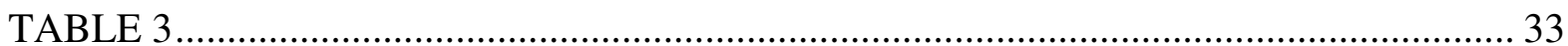




\section{LIST OF FIGURES}

FIGURE 1 - Example of the Task Assignment Problem ........................................................ 11

FIGURE 2 - Pseudocode for the General Greedy Algorithm ................................................ 17

FIGURE 3 - Problem Specific Pseudocode for Greedy Algorithm........................................ 18

FIGURE 4 - Pseudocode for one iteration of basic Meta-RaPS procedure .............................. 21

FIGURE 5 - Problem Specific Flowchart for Greedy Algorithm........................................... 22

FIGURE 6 - Pseudocode for Modified Greedy Algorithm with Meta-RaPS .......................... 23

FIGURE 7 - Effect of Percent Priority and Percent Restriction on Best Total Cost .............. 28

FIGURE 8 - Effect of Percent Priority and Percent Restriction on Average Total Cost........ 29

FIGURE 9- Effect of Percent Priority and Percent Restriction on Standard Deviation ......... 29

FIGURE 10 - 2D Representations of Figures 7, 8 and 9 ................................................... 30 


\section{INTRODUCTION}

The problem of assigning workers to tasks based on worker skill competencies and task skill requirements is one that nearly every company faces. Whether the company wants to efficiently assign workers to tasks for ongoing production or for a series of smaller projects, having a good method for making these assignments in a manner that minimizes cost is extremely important.

It is likely that if management is not using a consistent method to determine worker to task assignments, it will not be able to develop a low-cost assignment or even a feasible assignment at all. The assignment chosen by management may create a situation where the work cannot be completed by the deadline if careful attention is not paid to the time required to train each worker as well as worker capacities. Additionally, if the project is on a tight budget, a bad assignment can put the cost-effectiveness of the entire project into jeopardy. As the problem size grows larger, these negative effects are exacerbated. It is therefore obvious that a consistent method for worker to task allocations is needed.

Software tools are currently available to help companies make better worker to task assignments. These tools, however, do not incorporate means to deal with situations where further training of employees is necessary in order to complete a task. For cases like this, it must be determined which workers to train in which tasks in order to develop the lowest total training cost for the assignment. Both time to train and cost to train must be incorporated. To accomplish this, Depuy et al. 2006 developed a math model that includes these two variables when determining optimum worker to task assignments. That model is discussed in detail in Section II, Problem Description. 
It is typically more cost effective for companies to train their current employees to meet task competency requirements as opposed to firing workers with inadequate skill competencies and hiring those with more skills. Therefore, the motivation for this project is to change the current workforce to meet the project requirements. This will allow companies to begin planning for the future instead of simply making assignments for the present.

In addition, the results show management which skills to hold training sessions for, and how many employees need that training. Anticipating future training needs and developing employees to meet their personal career goals will be easier. Management can fit employees into training sessions that are already in place to meet employee career development interests. 


\section{PROBLEM DESCRIPTION}

The following terms and definitions are necessary in order to best understand this problem.

- Project - a combination of a few or many tasks that results in the final product or service (for example assembling the frame of an automobile or producing the automobile in its entirety)

- Task - one specific job to be completed by an employee (such as welding two pieces of metal together)

- Skill - a competency requirement in order to complete the job (for instance welding)

- Skill Level - the level of competency of a certain skill held by a worker or required by a task (such as novice, proficient, or expert in welding)

When there is a gap between a worker's current skill level and the required skill level, additional training is necessary. Figure 1 illustrates those skills gaps for an example task assignment problem. As mentioned earlier, Depuy et al. 2006 developed a math model that finds the optimal assignment for the Crane Division, Naval Surface Warfare Center (NSWC). This model assumes that once trained in a specific skill, the worker does not need to be retrained in order to complete a different task requiring that skill. The objective function is to minimize the total training cost. 


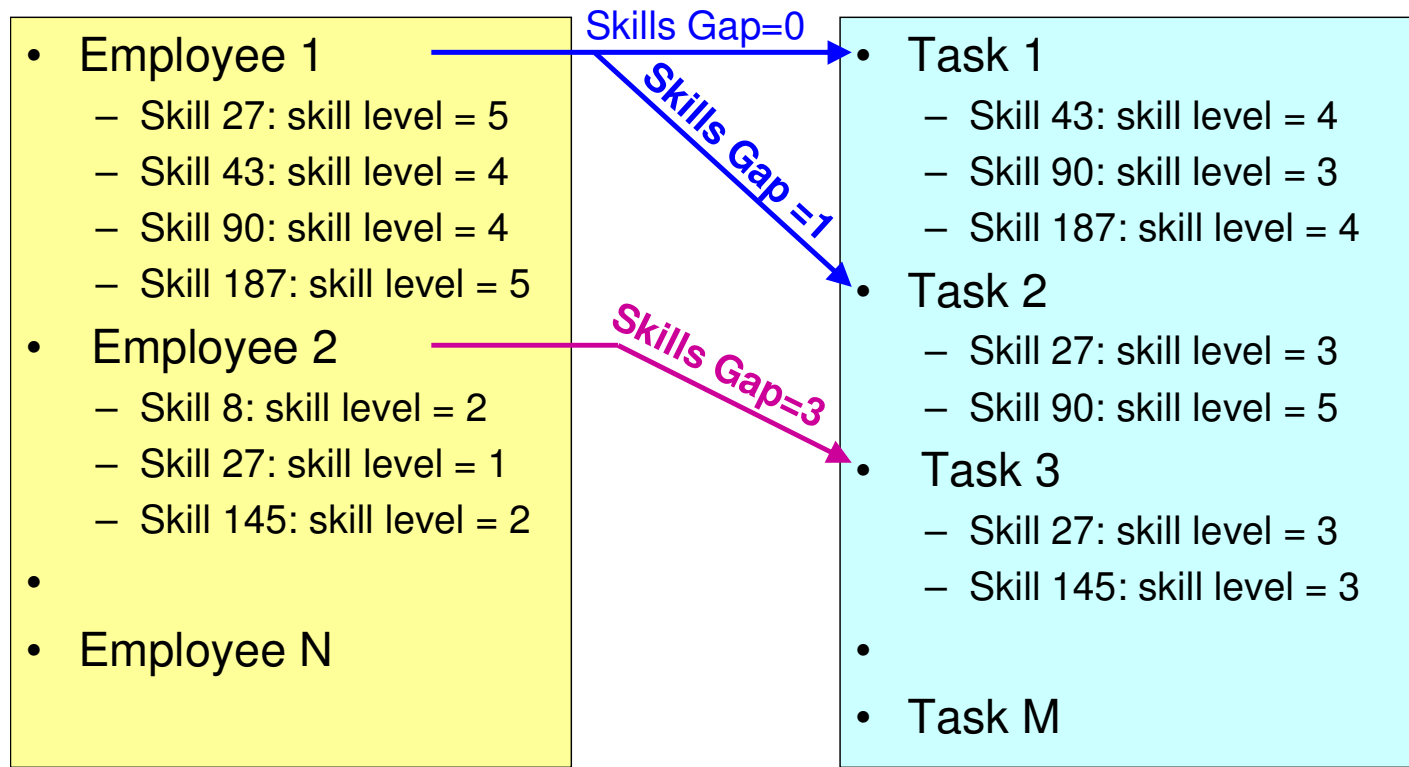

FIGURE 1 - Example of the Task Assignment Problem

The Depuy et al. 2006 model is as follows:

\section{Parameters:}

$\{\mathrm{j}\}=$ set of skills needed to perform task $\mathrm{j}$

$\mathrm{S}_{\mathrm{ik}}=$ worker i's skill level for skill $\mathrm{k}$

$\mathrm{R}_{\mathrm{jk}}=$ required skill level for task j's skill $\mathrm{k}$

$\mathrm{T}_{\mathrm{j}}=$ length (\# hrs) of task $\mathrm{j}$

$\mathrm{A}_{\mathrm{i}}=$ capacity (\# hrs) of worker $\mathrm{i}$

$\mathrm{C}_{\mathrm{klm}}=$ cost associated with raising a worker's skill level on skill $\mathrm{k}$ from level 1 to level $\mathrm{m}$ $\mathrm{E}_{\mathrm{klm}}=$ time required (\# hrs) to raise a worker's skill level on skill $\mathrm{k}$ from level 1 to level $\mathrm{m}$

\section{Decision Variables:}

$\mathrm{X}_{\mathrm{ij}}=\left\{\begin{array}{l}1, \text { worker } i \text { is assigned to task } j \\ 0, \text { otherwise }\end{array}\right.$ 
$Z_{i k S_{i k} m}=\left\{\begin{array}{l}1, \text { worker i receives training on skill } k \text { to raise skill level from } \\ \text { Sik to } m \\ 0, \text { otherwise }\end{array}\right.$

$\mathrm{N}_{\mathrm{ik}}=\left\{\begin{array}{l}1, \text { worker } i \text { does not need further training in skill } k \\ 0, \text { otherwise }\end{array}\right.$

\section{Objective Function:}

Minimize Training Cost Minimize $\sum_{i} \sum_{k} \sum_{m} C_{k S_{i k} m} Z_{i k S_{i k} m}$

\section{Constraints:}

Determine Needed Training $S_{i k} N_{i k}+\sum_{m>S_{i k}}^{5} m Z_{i k S_{i k} m} \geq R_{j k} X_{i j} \quad \forall i, j, k \in\{j\}$

$$
N_{i k}+\sum_{m>S_{i k}}^{5} Z_{i k S_{i k} m}=1
$$

All tasks assigned

$$
\sum_{i} X_{i j}=1
$$

Worker Capacity

$$
\sum_{j} T_{j} X_{i j}+\sum_{k} \sum_{m} E_{k S_{i k} m} Z_{i k S_{i k} m} \leq A_{i}
$$

Binary Variables

$$
X_{i j} \in\{0,1\}, \quad Z_{i k S_{i k} m} \in\{0,1\}, \quad N_{i k} \in\{0,1\}
$$

Equation 1 is the objective function minimizing the total training cost. Additional training required in order for a worker to be competent enough to complete a particular task is calculated in constraints 2 and 3. All of skills of the task are included when calculating the training needs for the worker. The variable $\mathrm{N}_{\mathrm{ik}}$ represents when a worker has met the skill level requirement that the task requires and therefore does not need additional training. Next, the model ensures that every task is assigned, but only to one worker (constraints 4). Finally, the total workload for a worker, including training time and task time, must be within the capacity of the worker. This is ensured through constraints 5 . 
Although this model can solve small problems in an acceptable amount of time, as the problem size increases, run-time also increases to an unsatisfactory level. For example, solving a 9 worker, 13 task and 11 skill problem optimally required 18 hours (see dataset in Appendix A). By utilizing a heuristic, a solution can be found in a reasonable timeframe, but the benefit of an optimal solution must be sacrificed. As an extension of the work completed by Depuy et al., this project focuses on developing a heuristic that will produce a good solution, although likely to be suboptimal, in a reasonable amount of time. The Greedy Algorithm meets the needs of this problem by finding a good solution quickly. For the 9 worker, 13 task and 11 skill problem mentioned above, the Greedy Algorithm finds a solution in under 1 minute.

The downside of the Greedy Algorithm is that it is deterministic. In theory, heuristics such as the Greedy Algorithm have the potential to find the optimal answer, but it is likely that they will be trapped in a local minimum. Modifying the algorithm to produce more than one assignment would allow for the best assignment from a group of possibilities to be chosen, thereby increasing the likelihood that the global optimum will be found. Multiple techniques are available to force the Greedy Algorithm to produce more than one result. These include Genetic Algorithms, Simulated Annealing, Tabu Search and Neural Networks. Each of are discussed in Section III, Background.

This method also forces the assignment of at least one task to each employee, even if that means paying a worker to receive additional training when a more skilled worker has the capacity to complete that task; ensuring that even those employees with the least training and experience will have an opportunity to receive additional training and gain more work experience. In addition, more skilled workers are typically those 
who are older and have been with the company longer, and are therefore closer to retirement. If companies only assign tasks to highly skilled workers, they will eventually run into problems when those employees retire. To prepare for the future, companies must have a plan to train newer employees so they will be prepared when skilled workers retire. 


\section{BACKGROUND}

The task assignment problem has been approached from various perspectives. Several researchers have investigated academic exam and proctor scheduling, while others have explored the task assignment problem as it relates to the non-academic workworld, such as telephone operators and construction work.

\section{A. Academic Applications}

Scheduling final examinations is a problem that universities face each term. Carter, LaPorte and Chinneck (1994) developed EXAMINE, a PC based scheduling system for exams which allows all examinations to take place in a limited time period, without conflicts, while satisfying room availability constraints. The aim of the authors was to develop a heuristic algorithm that was robust, flexible, quick and user-friendly. The algorithm progressively assigns examinations to periods while optimizing the objective function. Once a feasible schedule is created, the algorithm runs a post optimization phase.

Assigning proctors to the final examinations was approached by Awad and Chinneck (2000). Due to proctor training, preferences, and other constraints, finding a good feasible solution can be problematic. To replace time consuming manual assignments, a computer based system was developed. Assignments are based on a combination of problem-specific heuristics and a genetic-algorithm structure. The authors used Microsoft Access ${ }^{\circledR}$ and Visual Basic ${ }^{\circledR}$ to create an interface and database system for making the assignments. 


\section{B. Non-academic Applications}

In 1997, Thompson developed a process for assigning telephone operators to shifts at New Brunswick Telephone Company. The specialized shift assignment heuristic (SSAH) assigns shifts to employees based on seniority until a full feasible schedule is created. Then an improvement procedure tests all two-way shift swaps between employee pairs, and makes changes when a more cost effective schedule is found. The author utilized spreadsheet macros incorporated with a stand-alone procedure to create an easy to use PC based technique.

The problem of assigning managers to construction projects at Heery International was approached using a spreadsheet optimization technique (LeBlanc et al., 2000). This method is effective for problems up to 114 projects. This method is easy to modify as new projects come and new managers are hired, and as projects are completed and managers resign. Although this research was specific to assigning managers to construction projects, it is applicable for assigning managers to projects in any organization. 


\section{WORKERSKILLS ASSIGNMENT PROCEDURE}

\section{A. Greedy Algorithm}

A Greedy Algorithm essentially makes the best, near-sighted decision at each stage of the problem in hopes of finding a good solution. In this case, the algorithm will choose the lowest cost worker to task allocation as the first assignment, then choose the next lowest cost worker to task assignment, and so on until all tasks have been assigned. After each assignment, the worker skill set is updated based on any training that he or she may have received (See Figure 2). It is possible that choosing these local minimums will result in the global minimum training cost, but it is more likely that this method alone will not be optimal.

Find training cost for each worker to complete each task Do Until all tasks assigned

Find worker to task assignment with lowest training cost Assign task to worker Update worker skill set based on assignment

Loop

Calculate and print total training cost

FIGURE 2 - Pseudocode for the General Greedy Algorithm

The Greedy Algorithm shown in Figure 2 does not include the requirement that at least one task is assigned to each worker and that management is changing the current workforce to meet project needs instead of hiring new workers with more skill competencies. This is accomplished through two loops in the program. The first loop is a slight modification of the Greedy Algorithm that will eliminate a worker from the list of available workers once he or she has been assigned a task. After updating all of the 
worker skill sets based on their first task assignment, the second loop will assign the rest of the tasks to the workers based solely on minimum cost. See Figure 3 for these modifications.

Find training cost for each worker to complete each task

Do Until each worker is assigned one task

Calculate the sum training cost if worker completes all tasks

Find worker with maximum sum training cost

Find lowest cost task for this worker

Assign task to worker

Remove worker from available worker list

Loop

Update worker skill sets based on assignments

Do Until all tasks assigned

Calculate the task sum cost for each task if all workers complete the task

Find task with maximum sum cost

Find lowest cost worker for this task

Assign worker to task

Remove task from available worker list

Loop

Update worker skill levels based on training received

Calculate and print total training cost

FIGURE 3 - Problem Specific Pseudocode for Greedy Algorithm

The theory behind finding the sum training cost in Figure 3 is that a worker who has a higher sum training cost is likely to require more training on average than a worker with a lower sum training cost. Likewise, the worker with the lowest sum training cost is likely to have more tasks where he or she requires little or no training. That person is therefore likely to be more flexible regarding which task should be assigned to them while still maintaining a very low cost. The worker with the highest sum training cost is likely to have very few or no tasks with low training costs. Therefore, that worker is assigned his or her lowest cost task in order to minimize the training cost for that worker. Other workers with lower sum training costs (i.e. more flexibility with assignments) can 
then be assigned the tasks that remain. Based on this theory, the algorithm finds the worker with the maximum sum training cost, and then finds the task with the lowest training cost for that worker. Then the skill levels for that worker are updated based on any training he or she may have received. The algorithm repeats this procedure until all workers have at least one task. The second loop in the program operates with the same theory as just described. The task with the maximum sum cost is selected, and then the worker with the lowest training cost for that task is chosen.

\section{B. Modified Greedy Algorithm}

As stated earlier, heuristics have the chance to find the optimal answer, but can get trapped in a local optimal solution. Introducing randomness is a common method of dealing with this problem. The Greedy Algorithm alone will find a good answer, but randomizing parts of the algorithm will ensure that multiple answers are possible. Modifying the algorithm such that it sometimes accepts an assignment that temporarily worsens the objective function will succeed in leaving the local optimum and possibly find the global optimal solution. Other modern heuristics, called meta-heuristics, like Genetic Algorithms, Simulated Annealing, Tabu Search and Neural Networks do just that. Another meta-heuristic, Meta-RaPS, developed by Depuy and Whitehouse (2000) is the chosen method for this problem because it is easy to understand and implement while realizing good results.

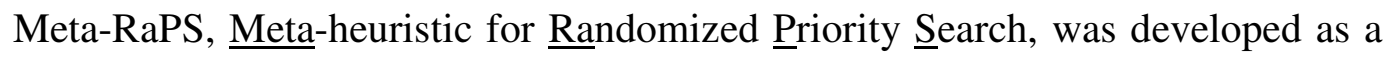
part of research on applying a modified COMSOAL (Computer Method of Sequencing Operations for Assembly Lines) approach to several combinatorial problems. Originally an approach to the assembly line balancing problem (Arcus, 1966), the theory behind 
COMSOAL can also be applied to other problems. Through modifications, COMSOAL has evolved into Meta-RaPS. With Meta-RaPS, Depuy and Whitehouse were able to preserve the underlying idea of COMSOAL, but their modification is noticeably different in practice. Therefore, their approach was presented as Meta-RaPS in 2000.

Other meta-heuristics utilize some device to avoid local minima, and Meta-RaPS is no different. By incorporating an element of randomness, Meta-RaPS is able to modify construction heuristics, and avoid local minima. Using priority rules in a randomized fashion, Meta-RaPS creates a different solution at each iteration and after a number of iterations, Meta-RaPS reports the best solution.

Construction heuristics develop solutions by building up elements with the best priority values to form the final solution. Meta-RaPS modifies this method by sometimes forcing the construction heuristic to choose an element that does not have the best priority value. Three user-defined parameters are used by Meta-RaPS to introduce randomness: percent priority, percent restriction, and percent improvement. Choosing parameters for this model is described in Section V, Results.

The percent priority parameter chooses how often the best priority element is chosen and added to the solution. The rest of the time, the percent restriction parameter is used to choose the next element added to the solution. Percent restriction decides how close to the best priority value the next element needs to be. All values within the percent restriction of the best priority value will be included in the group of available elements. The next element is randomly chosen from the group of available elements. This technique of using percent priority and percent restriction to choose the next element is performed for all elements until a final solution is found (Figure 4). The percent 
improvement parameter is used to determine when to run an improvement heuristic. If the solution for an iteration is within the percent improvement of the best unimproved solution so far, an improvement heuristic (neighborhood search) is run.

\section{Do Until feasible solution generated}

Find training cost for each feasible worker to task assignment

Find lowest training cost

$\mathrm{P}=\mathrm{RND}(1,100)$

If $\mathrm{P}<=\%$ priority Then

Add assignment with lowest training cost to solution

Else

Form 'available list' of all assignments whose priority values are within \%restriction of lowest cost assignment

Randomly choose assignment from available list and add to solution

End Until

Calculate and Print solution value

FIGURE 4 - Pseudocode for one iteration of basic Meta-RaPS procedure

There are four locations where the Meta-RaPS procedure can be inserted into the general Greedy Algorithm. Two of those locations are in the first loop that assigns each worker one task, and the other two locations are in the final loop assigning all of the remaining tasks. The flowchart in Figure 5 is a representation of the pseudocode from Figure 2. The emphasized boxes are the four locations where Meta-RaPS can be implemented. 


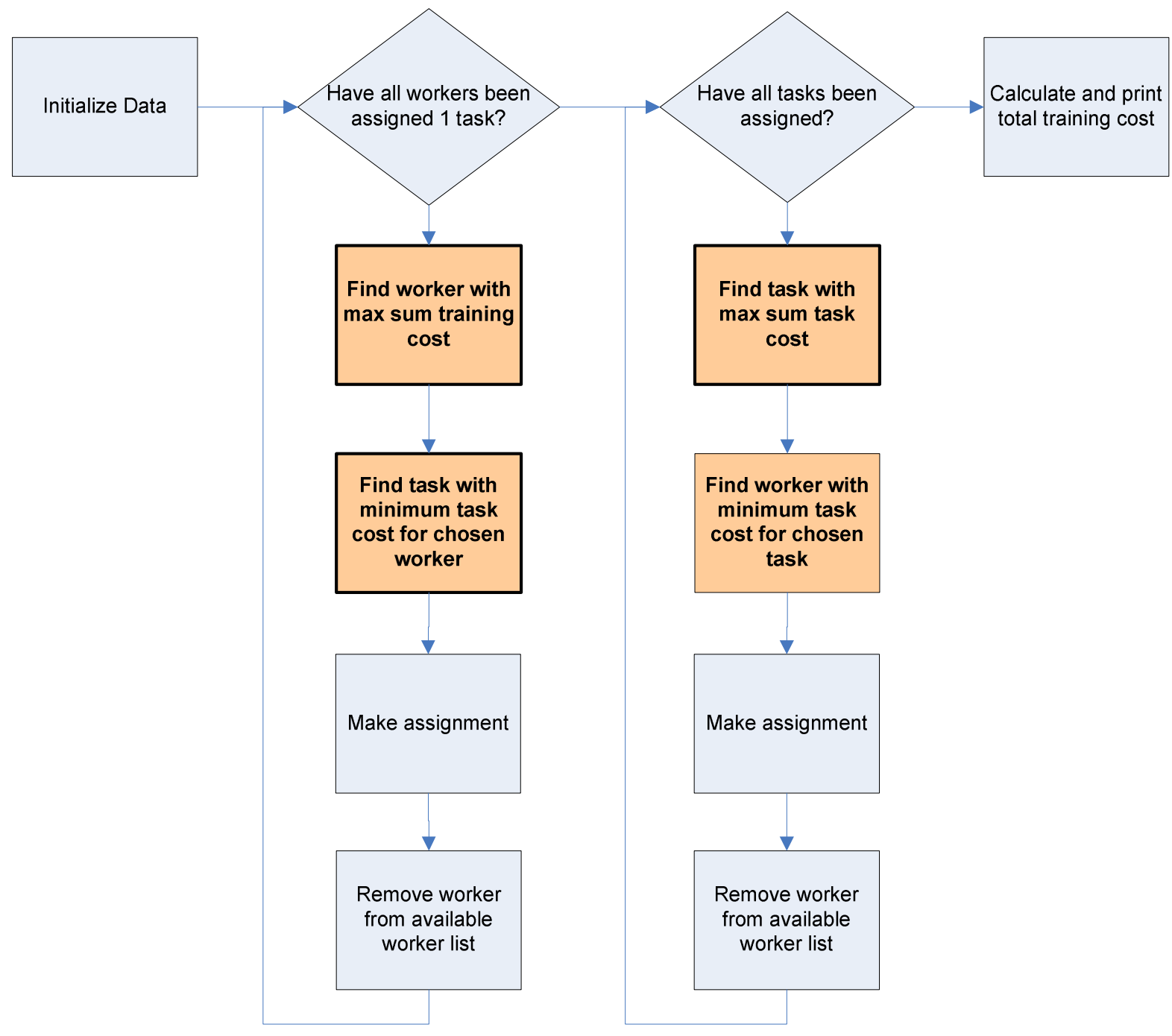

FIGURE 5 - Problem Specific Flowchart for Greedy Algorithm

Meta-RaPS has been implemented in all four of the above locations for this problem in order to maximize the ability of the heuristic to find the best answer possible. The pseudocode for this implementation is given in Figure 6. Instead of including all three parameters in this problem, only percent priority and percent restriction were used. Coding an improvement algorithm for this problem can be a future project.

Do Until each worker is assigned one task

Find feasible worker with max sum training cost across all tasks 


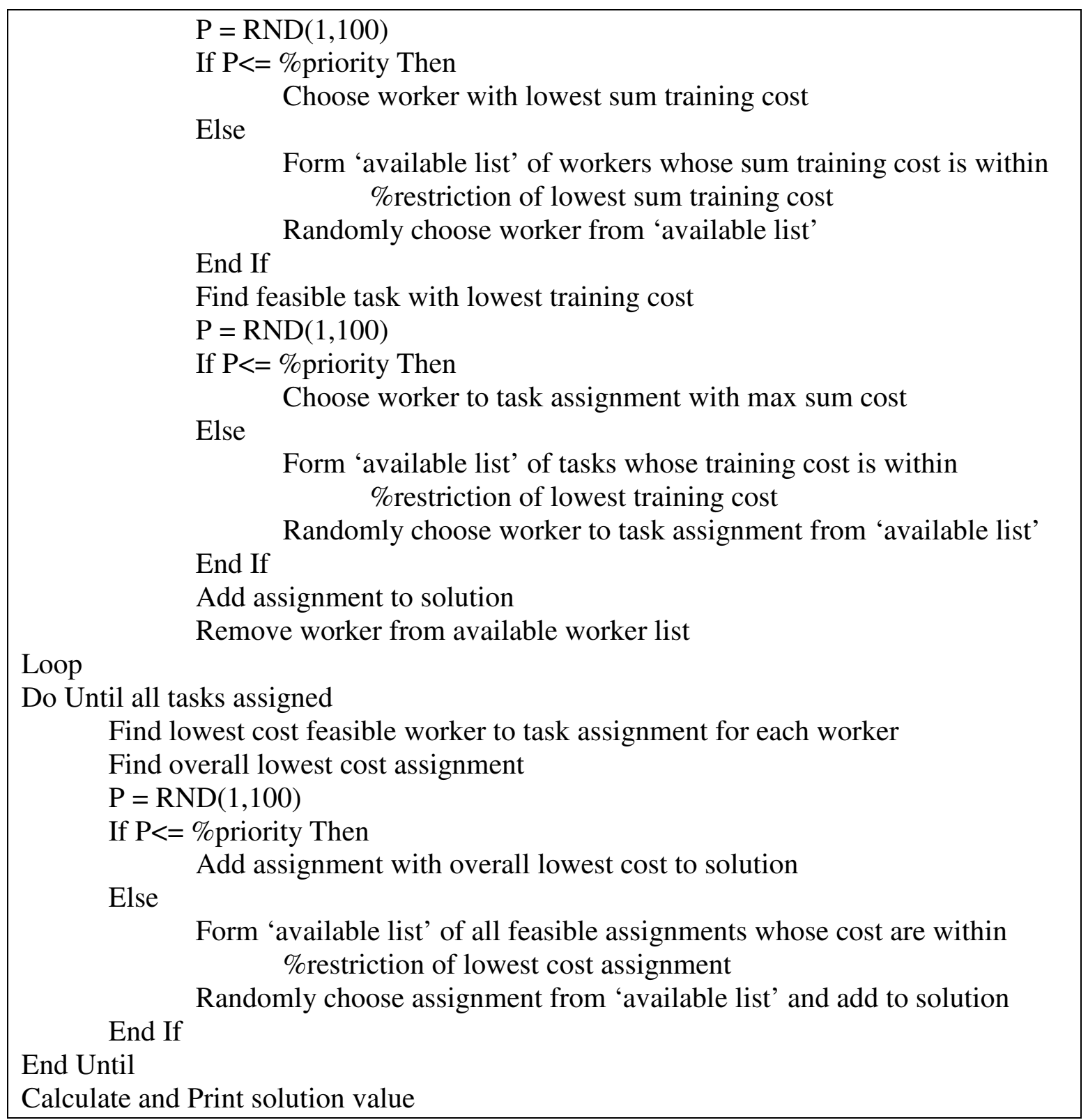

FIGURE 6 - Pseudocode for Modified Greedy Algorithm with Meta-RaPS 


\section{RESULTS}

Microsoft Excel® VBA 2007 was used to program this modified Greedy Algorithm (see Appendix B). Other programming languages could be more efficient solving this problem, but Excel® VBA is more useful in the corporate world. One benefit is that no new programs such as Lingo ${ }^{\circledR}$ or another stand-alone program have to be purchased and installed in order to run the analysis. Excel® VBA is also very useful for developing functional outputs specific to a company's precise needs, and is easily compatible with other Office ${ }^{\circledR}$ programs such as Project ${ }^{\circledR}$ and Access ${ }^{\circledR}$.

As stated earlier, the parameters used by Meta-RaPS are user-defined, and must be determined. If desired, this heuristic can mimic both the math model and traditional Greedy Algorithm by making the parameters specific values. A percent priority values of 0 and percent restriction values of 100 for each Meta-RaPS instance will find the optimal assignment. Percent priority values of 100 will mimic the traditional Greedy Algorithm.

At each use of Meta-RaPS, the percent priority and percent restriction values can be different. For simplicity and ease of use, however, each parameter is held constant for each application. The traditional method for choosing the values of these parameters has been trial and error, and therefore is the method used for choosing the parameters for this problem.

A sample dataset with 9 workers, 13 tasks and 11 skills was used to test this heuristic (see Appendix B). Other sample datasets (see Appendices A and C) are used to confirm the results from this sample dataset, and will be discussed in Section VI, Conclusions and Recommendations. In order to ensure that the solution values for the test dataset were accurate, 5000 iterations were run and the best solution was chosen. 
This best total cost as well as the average total cost and standard deviation over all iterations are given in the Table 1 for each percent priority, percent restriction pair. It is important to ensure that these values are optimized when choosing the percent priority and percent restriction to be used for future tests.

TABLE 1

\section{SUMMARY OF PERCENT PRIORITY AND PERCENT RESTRICTION ANALYSIS}

\begin{tabular}{|c|c|c|c|c|}
\hline $\begin{array}{l}\text { Percent } \\
\text { Priority }\end{array}$ & $\begin{array}{c}\text { Percent } \\
\text { Restriction }\end{array}$ & $\begin{array}{c}\text { Best Total } \\
\text { Cost }\end{array}$ & $\begin{array}{c}\text { Average } \\
\text { Total Cost }\end{array}$ & $\begin{array}{l}\text { Standard } \\
\text { Deviation }\end{array}$ \\
\hline 10 & 10 & 394 & 440 & 23 \\
\hline 10 & 20 & 386 & 438 & 24 \\
\hline 10 & 30 & 386 & 449 & 28 \\
\hline 10 & 40 & 386 & 467 & 33 \\
\hline 10 & 50 & 386 & 485 & 35 \\
\hline 10 & 60 & 395 & 502 & 38 \\
\hline 10 & 70 & 394 & 515 & 43 \\
\hline 10 & 80 & 383 & 515 & 44 \\
\hline 10 & 90 & 395 & 523 & 44 \\
\hline 20 & 10 & 394 & 442 & 23 \\
\hline 20 & 20 & 386 & 439 & 24 \\
\hline 20 & 30 & 386 & 447 & 28 \\
\hline 20 & 40 & 386 & 464 & 33 \\
\hline 20 & 50 & 386 & 479 & 35 \\
\hline 20 & 60 & 387 & 493 & 39 \\
\hline 20 & 70 & 390 & 501 & 44 \\
\hline 20 & 80 & 380 & 504 & 44 \\
\hline 20 & 90 & 390 & 512 & 45 \\
\hline 30 & 10 & 394 & 444 & 22 \\
\hline 30 & 20 & 386 & 439 & 24 \\
\hline 30 & 30 & 386 & 446 & 28 \\
\hline 30 & 40 & 386 & 461 & 33 \\
\hline 30 & 50 & 386 & 475 & 35 \\
\hline 30 & 60 & 389 & 486 & 37 \\
\hline 30 & 70 & 390 & 495 & 42 \\
\hline
\end{tabular}




\begin{tabular}{|c|c|c|c|c|}
\hline 30 & 80 & 380 & 494 & 43 \\
\hline 30 & 90 & 380 & 501 & 44 \\
\hline 40 & 10 & 394 & 445 & 22 \\
\hline 40 & 20 & 386 & 440 & 24 \\
\hline 40 & 30 & 386 & 444 & 27 \\
\hline 40 & 40 & 386 & 457 & 31 \\
\hline 40 & 50 & 386 & 468 & 35 \\
\hline 40 & 60 & 386 & 477 & 37 \\
\hline 40 & 70 & 386 & 482 & 41 \\
\hline 40 & 80 & 380 & 484 & 42 \\
\hline 40 & 90 & 380 & 490 & 42 \\
\hline 50 & 10 & 394 & 449 & 21 \\
\hline 50 & 20 & 386 & 443 & 23 \\
\hline 50 & 30 & 386 & 443 & 26 \\
\hline 50 & 40 & 386 & 454 & 30 \\
\hline 50 & 50 & 386 & 463 & 32 \\
\hline 50 & 60 & 388 & 469 & 35 \\
\hline 50 & 70 & 387 & 471 & 38 \\
\hline 50 & 80 & 387 & 474 & 39 \\
\hline 50 & 90 & 388 & 479 & 40 \\
\hline 60 & 10 & 394 & 452 & 19 \\
\hline 60 & 20 & 386 & 446 & 23 \\
\hline 60 & 30 & 386 & 444 & 25 \\
\hline 60 & 40 & 386 & 453 & 29 \\
\hline 60 & 50 & 388 & 460 & 31 \\
\hline 60 & 60 & 388 & 466 & 32 \\
\hline 60 & 70 & 388 & 464 & 35 \\
\hline 60 & 80 & 387 & 467 & 37 \\
\hline 60 & 90 & 388 & 471 & 37 \\
\hline 70 & 10 & 394 & 454 & 17 \\
\hline 70 & 20 & 386 & 450 & 21 \\
\hline 70 & 30 & 386 & 446 & 24 \\
\hline 70 & 40 & 386 & 453 & 26 \\
\hline 70 & 50 & 386 & 457 & 29 \\
\hline 70 & 60 & 388 & 461 & 29 \\
\hline 70 & 70 & 388 & 458 & 31 \\
\hline 70 & 80 & 388 & 462 & 33 \\
\hline
\end{tabular}




\begin{tabular}{|l|l|l|l|l|}
\hline 70 & 90 & 388 & 465 & 34 \\
\hline 80 & 10 & 394 & 457 & 14 \\
\hline 80 & 20 & 388 & 453 & 19 \\
\hline 80 & 30 & 386 & 449 & 22 \\
\hline 80 & 40 & 394 & 455 & 24 \\
\hline 80 & 50 & 394 & 455 & 25 \\
\hline 80 & 60 & 394 & 458 & 26 \\
\hline 80 & 70 & 387 & 453 & 29 \\
\hline 80 & 80 & 390 & 457 & 30 \\
\hline 80 & 90 & 390 & 459 & 29 \\
\hline 90 & 10 & 394 & 460 & 11 \\
\hline 90 & 20 & 388 & 458 & 14 \\
\hline 90 & 30 & 388 & 455 & 17 \\
\hline 90 & 40 & 388 & 457 & 18 \\
\hline 90 & 50 & 388 & 458 & 20 \\
\hline 90 & 60 & 394 & 459 & 20 \\
\hline 90 & 70 & 390 & 455 & 23 \\
\hline 90 & 80 & 388 & 457 & 23 \\
\hline 90 & 90 & 390 & 458 & 24 \\
\hline
\end{tabular}

The charts in Figures 7 through 10 were created in Matlab® 7.4 to illustrate the effect of percent priority and percent restriction on the response variables above. Figures 7 through 9 are 3D maps, and Figure 10 shows a 2D illustration of Figures 7 through 9. It is difficult to determine what the best parameter values are from the Best Total Cost graphs, but percent priority values of 20,40 and 40 look good as do percent restriction values of 80 and 90 . The Average Total Cost graphs are more interesting. There is a trend in the percent priority that indicates that as the percent priority increases, percent restriction has a lower effect on the response. This is evident in the fact that the range decreases on the percent priority graph for that response in Figure 10. Also, there is an remarkable trend in the percent restriction graph for the Average Total Cost in Figure 10. It appears that the graph flip-flops at a percent restriction value of 30. Finally, the 
Standard Deviation graphs indicate that higher values of percent priority and lower values of percent restriction create solutions with less deviation.

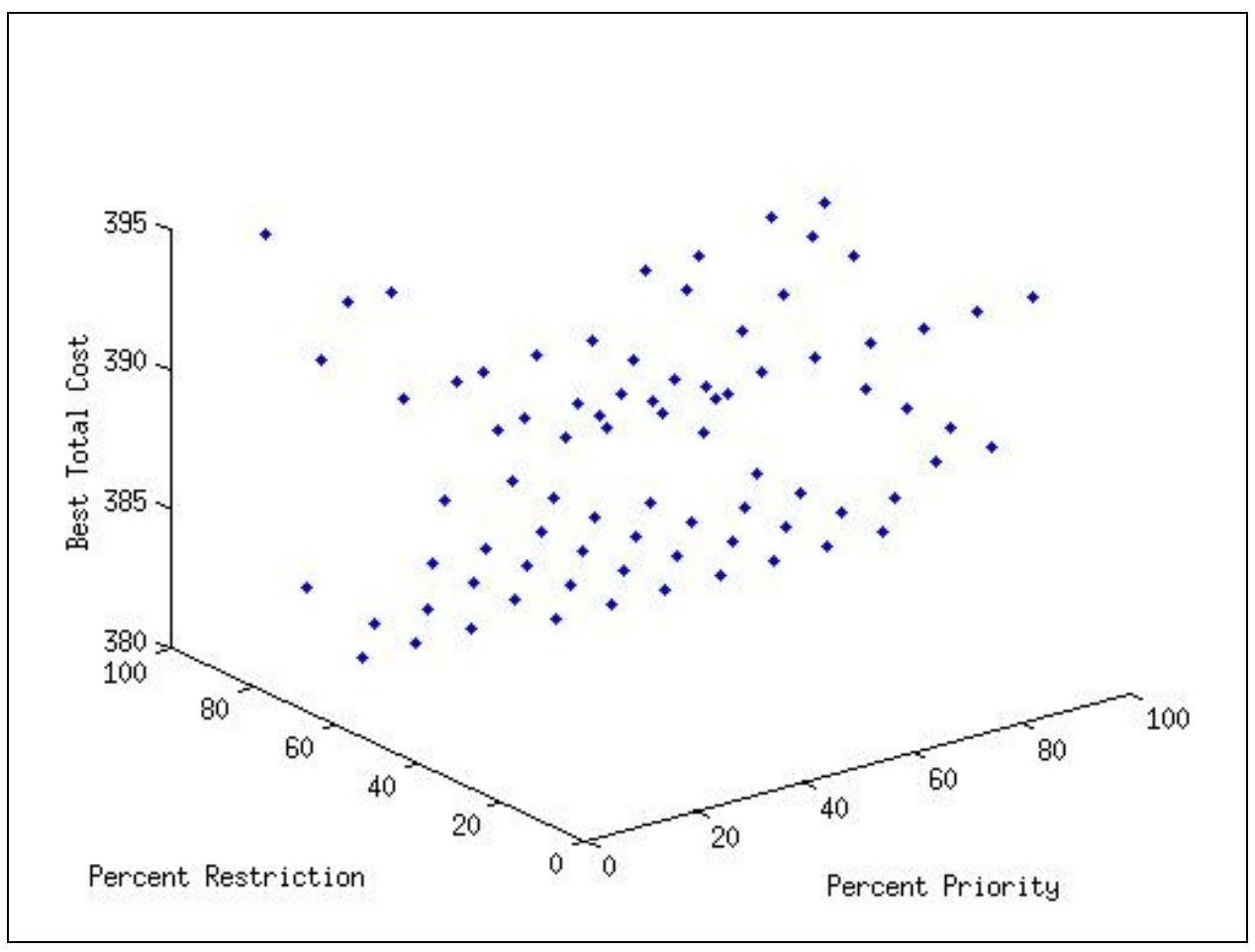

FIGURE 7 - Effect of Percent Priority and Percent Restriction on Best Total Cost 


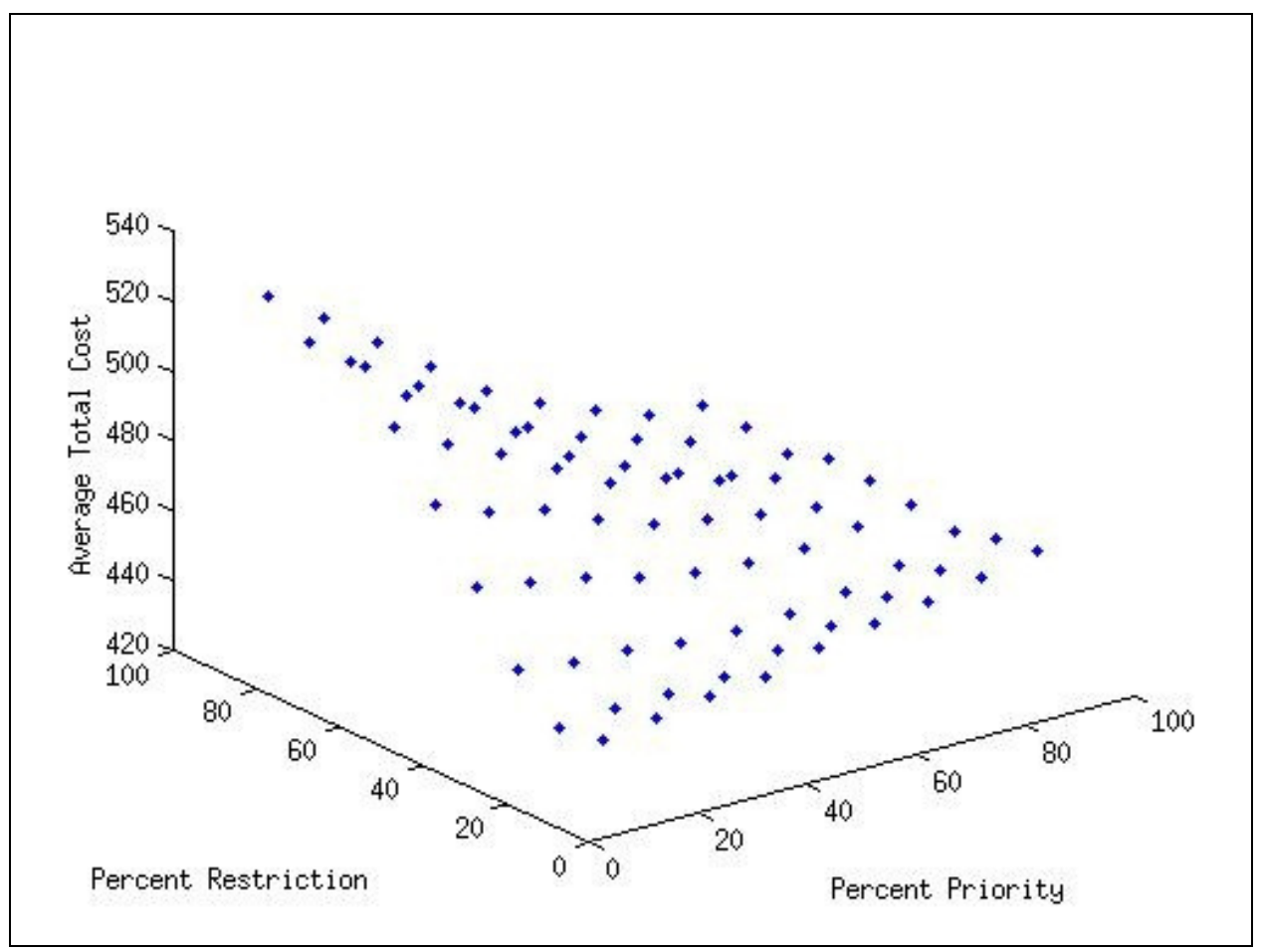

FIGURE 8 - Effect of Percent Priority and Percent Restriction on Average Total Cost

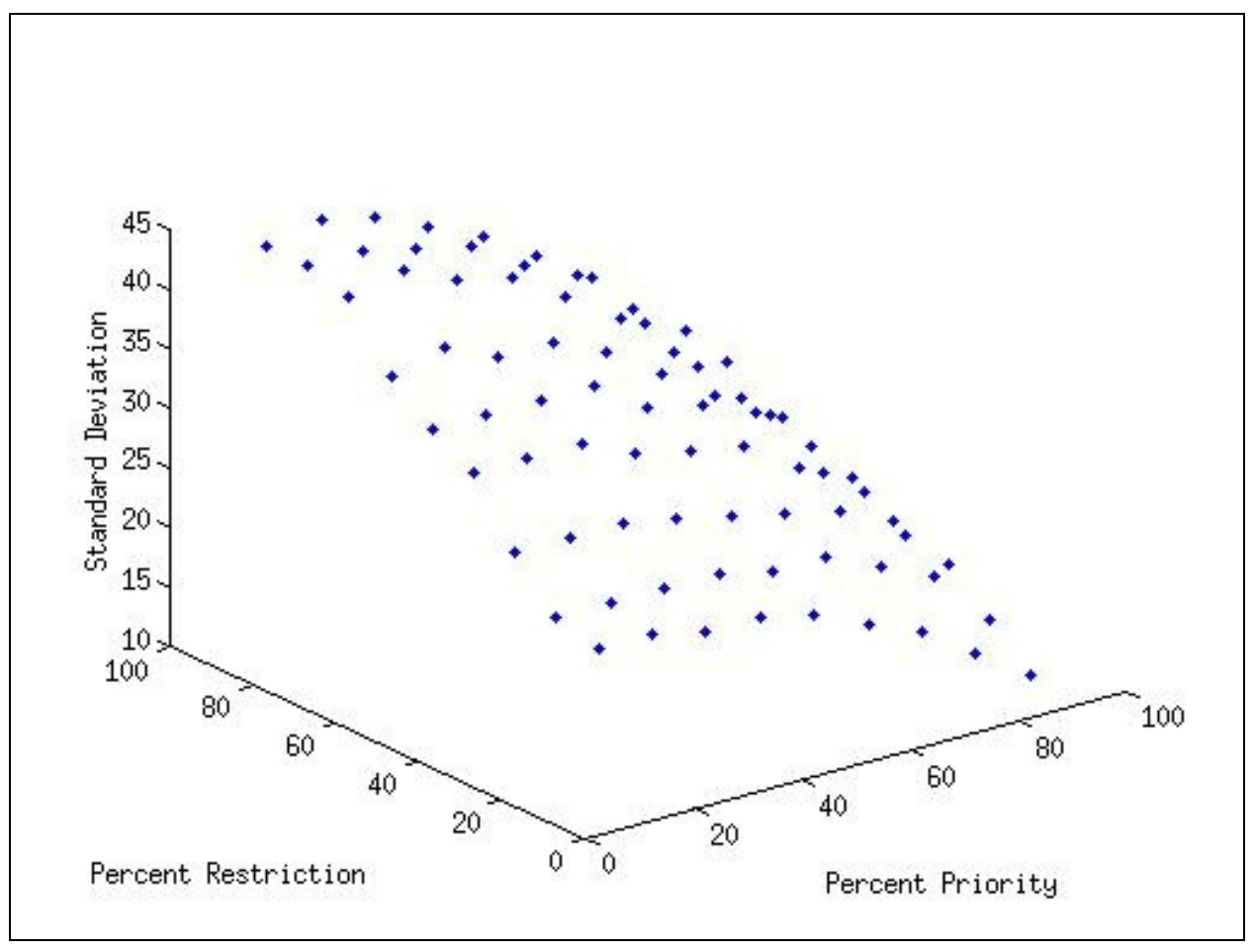

FIGURE 9- Effect of Percent Priority and Percent Restriction on Standard Deviation 

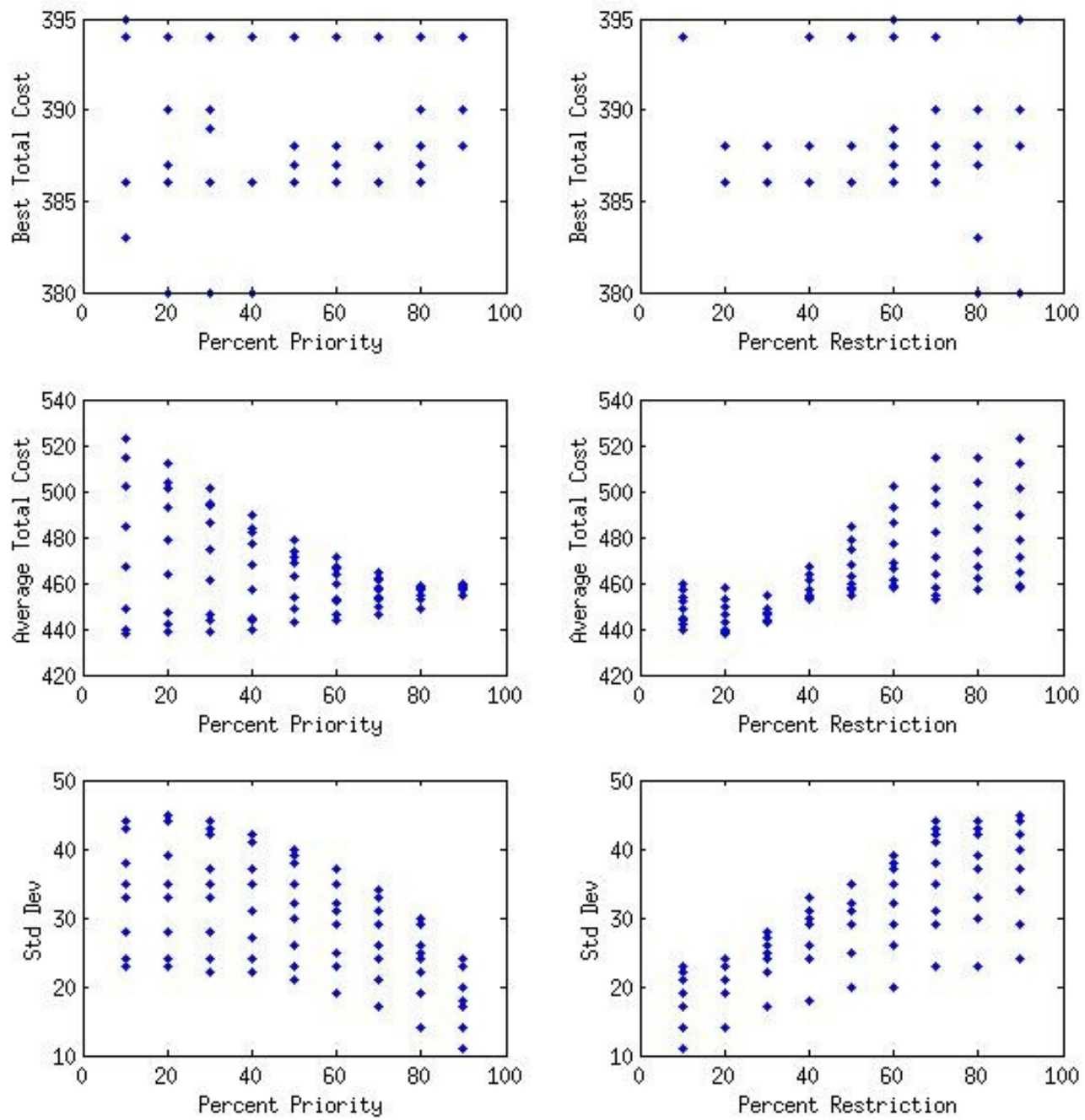

FIGURE 10 - 2D Representations of Figures 7, 8 and 9 
All of this information aids in the understanding of the problem, but it still isn't clear which values are the best. Since best total cost is the value that is of most interest, it is expected that a percent priority value of 30 and a percent restriction value of 80 will create the best results. This can be confirmed using the other 3 sample datasets in Appendices A and C. These results are presented in Section VI, Conclusions and Recommendations.

The Excel® VBA program runs using two macros. The first macro is used to create the input sheet (Appendix D). The user inputs the number of workers, skills and tasks into three message boxes, and the macro creates space for the user to input all of the relevant information. Please refer to Appendix E for screenshots of the input sheet. The second macro runs the heuristic and reports the solution in the Results and Output sheets (Appendices $\mathrm{F}$ and $\mathrm{G}$ ). The user can then use the solution information to plan training sessions for the employees. 


\section{CONCLUSIONS AND RECOMMENDATIONS}

The modified Greedy Algorithm works well for this problem. The test results for the sample data are shown in Table 2. For the parameter values chosen, the best solution is the same as the optimal solution. The average solution is $30 \%$ greater than optimal. This can be combated by ensuring that there are enough iterations to get the lowest value possible. For this dataset, 5000 iterations appears to be adequate.

TABLE 2

OPTIMAL AND HEURISTIC RESULTS FOR TEST DATASET

\begin{tabular}{|c|c|c|}
\hline \multicolumn{2}{|c|}{ Optimal Solution } & 380 \\
\hline \multirow{2}{*}{$\begin{array}{c}\text { Modified } \\
\text { Greedy } \\
\text { Algorithm }\end{array}$} & $\begin{array}{c}\text { Best } \\
\text { Solution }\end{array}$ & 380 \\
\cline { 2 - 3 } & $\begin{array}{c}\text { Average } \\
\text { Solution }\end{array}$ & 494 \\
\cline { 2 - 3 } & $\begin{array}{c}\text { Standard } \\
\text { Deviation }\end{array}$ & 43 \\
\hline
\end{tabular}

Table 3 below shows the results for two other datasets (see Appendices A and C). The best solution for the first dataset is within $2 \%$ of optimal, and the second dataset is within $4 \%$ of optimal. The average solution for the datasets are within $30 \%$ and $48 \%$, respectively. Although this isn't ideal, with 5000 iterations a very good solution is found. These results confirm that the selected parameter values from the previous test dataset work for other datasets as well, and prove it to be a fitting substitute for solving this problem optimally. 
TABLE 3

RESULTS FOR OTHER DATASETS

\begin{tabular}{|c|c|c|}
\hline \multirow{5}{*}{ Appendix A } & Optimal Solution & 393 \\
\cline { 2 - 3 } & $\begin{array}{c}\text { Best Heuristic } \\
\text { Solution }\end{array}$ & 400 \\
\cline { 2 - 3 } & $\begin{array}{c}\text { Average Heuristic } \\
\text { Solution }\end{array}$ & 511 \\
\cline { 2 - 3 } & $\begin{array}{c}\text { Heuristic Standard } \\
\text { Deviation }\end{array}$ & 38 \\
\hline \multirow{5}{*}{ Appendix C } & Optimal Solution & 297 \\
\cline { 2 - 3 } & $\begin{array}{c}\text { Best Heuristic } \\
\text { Solution }\end{array}$ & 309 \\
\cline { 2 - 3 } & $\begin{array}{c}\text { Average Heuristic } \\
\text { Solution }\end{array}$ & 440 \\
\cline { 2 - 3 } & $\begin{array}{c}\text { Heuristic Standard } \\
\text { Deviation }\end{array}$ & 53 \\
\hline
\end{tabular}

Although these sample datasets prove that the heuristic works well, real-world data can be used to further analyze the effect of different parameter settings. In addition to incorporating actual data, running multiple replications and running a factorial analysis using Minitab® or another statistical software package will aid in choosing proper parameter values. A factorial analysis can optimize the percent priority and percent restriction based on all three responses (best solution, average solution, and standard deviation). To do this, multiple replicates of the heuristic can be run using real-world data to create a full factorial experimental design. This analysis is essential for making this heuristic more marketable to companies. As more data is collected for the future analysis, the interesting trends shown in Figures 7 through 10 should be revisited to determine their cause. 
As mentioned earlier, it is typical to include an improvement algorithm as a part of the Meta-RaPS procedure, but it was not included at this time. Coding an improvement algorithm is a possible future endeavor, but would require future research into the best way to do this. In addition, it is not guaranteed that it will improve the solution much more than the current solution without increasing the amount of time.

Finally, the basic heuristic in Excel® VBA has been shown to be good for developing the solution, but does not present that solution in a format that is extremely functional for specific company use. The next step is to create company-specific userfriendly reports. This way it will be more appealing and easy to integrate into current employee training systems.

This new heuristic has many benefits, but also some limitations. Being able to solve problems in a fraction of the time as the optimal algorithm makes this heuristic a good option for companies needing quick solutions. Also, since the heuristic is able to find a solution within 5\% of optimal (with 5000 iterations), it is a good alternative for companies who are concerned about being as close to optimal as possible without while sacrificing hours finding a solution. The major limitation lies in the lack of testing. Since no real-world data was available, proving the effectiveness of the algorithm in the corporate world is difficult. Once more testing is completed using actual data and more user-friendly reports are available, this heuristic will be extremely useful for companies wishing to find a quick and reliable method for assigning workers to tasks. 


\section{REFERENCES}

Arcus, A. 1966. COMSOAL: A Computer method of sequencing operations for assembly lines. International Journal of Production Research 4:259-277.

Awad, R. and Chinneck, J. 2000. Proctor assignment at Carlton University. Interfaces 28:2:58-71.

Carter, M., Laporte, G., Chinneck, J. 1994. A general examination scheduling system. Interfaces 24:3:109-120.

DePuy, G., Whitehouse, G., 2000. Applying the COMSOAL computer heuristic to the constrained resource allocation problem, Computers and Industrial Engineering, 38, 413-422.

DePuy, G., Whitehouse, G., 2001. A simple and effective heuristic for the multiple resource allocation problem, International Journal of Production Research, 39 (14), 3275-3287.

Depuy, G., Moraga, R., Whitehouse, G. 2003. Meta-RaPS: A simple and effective approach for solving the traveling salesman problem. Transportation Research Part E. 212.

Depuy, G., Usher, J., and Arterburn, B. 2006. Workforce training schedule for logistics skills. CD-ROM Proceedings of the 2006 Industrial Engineerng Research Conference, May 20-24, Orlando, Florida.

LeBlanc, L., Randels, K., and Swan, T. K. 2000. Heery International's spreadsheet optimization model for assigning managers to construction projects. Interfaces 30:6:95-106.

Thompson, G. M. 1997. Assigning telephone operators to shifts at New Brunswick Telephone Company. Interfaces 27:4:1-11. 


\section{APPENDIX A}

\section{TEST DATASET 1}

\begin{tabular}{|c|c|}
\hline Number of workers & 9 \\
\hline Number of skills & 11 \\
\hline Number of tasks & 13 \\
\hline
\end{tabular}

\begin{tabular}{|c|c|c|c|c|c|c|c|c|c|c|c|}
\hline \multicolumn{10}{|c|}{$\begin{array}{c}\text { Worker Skill } \\
\text { Matrix }\end{array}$} & \multicolumn{10}{|c|}{$\begin{array}{c}\text { Skill } \\
\end{array}$} & $\begin{array}{c}\text { Skill } \\
2\end{array}$ & $\begin{array}{c}\text { Skill } \\
3\end{array}$ & $\begin{array}{c}\text { Skill } \\
4\end{array}$ & $\begin{array}{c}\text { Skill } \\
5\end{array}$ & $\begin{array}{c}\text { Skill } \\
6\end{array}$ & $\begin{array}{c}\text { Skill } \\
7\end{array}$ & $\begin{array}{c}\text { Skill } \\
8\end{array}$ & $\begin{array}{c}\text { Skill } \\
9\end{array}$ & $\begin{array}{c}\text { Skill } \\
10\end{array}$ & $\begin{array}{c}\text { Skill } \\
11\end{array}$ \\
\hline Worker 1 & 1 & 2 & 5 & 1 & 2 & 4 & 5 & 3 & 5 & 2 & 3 \\
\hline Worker 2 & 2 & 5 & 5 & 1 & 4 & 2 & 4 & 4 & 4 & 5 & 1 \\
\hline Worker 3 & 2 & 2 & 1 & 2 & 2 & 2 & 3 & 5 & 4 & 2 & 1 \\
\hline Worker 4 & 3 & 4 & 4 & 3 & 5 & 3 & 1 & 4 & 1 & 2 & 3 \\
\hline Worker 5 & 5 & 2 & 2 & 5 & 5 & 4 & 2 & 5 & 3 & 5 & 3 \\
\hline Worker 6 & 4 & 1 & 4 & 1 & 5 & 3 & 4 & 2 & 3 & 4 & 4 \\
\hline Worker 7 & 3 & 4 & 4 & 3 & 4 & 1 & 2 & 3 & 5 & 5 & 1 \\
\hline Worker 8 & 4 & 2 & 1 & 2 & 1 & 2 & 4 & 5 & 1 & 2 & 4 \\
\hline Worker 9 & 3 & 3 & 5 & 1 & 3 & 4 & 3 & 5 & 4 & 3 & 2 \\
\hline
\end{tabular}

The above matrix shows the current skill levels of each worker for each skill type.

\begin{tabular}{|c|c|c|c|c|c|c|c|c|c|c|c|}
\hline \multicolumn{2}{|c|}{$\begin{array}{c}\text { Task Skill } \\
\text { Matrix }\end{array}$} & & & & & & & & & & \\
\hline & $\begin{array}{c}\text { Skill } \\
1\end{array}$ & $\begin{array}{c}\text { Skill } \\
2\end{array}$ & $\begin{array}{c}\text { Skill } \\
3\end{array}$ & $\begin{array}{c}\text { Skill } \\
4\end{array}$ & $\begin{array}{c}\text { Skill } \\
5\end{array}$ & $\begin{array}{c}\text { Skill } \\
6\end{array}$ & $\begin{array}{c}\text { Skill } \\
7\end{array}$ & $\begin{array}{c}\text { Skill } \\
8\end{array}$ & $\begin{array}{c}\text { Skill } \\
9\end{array}$ & $\begin{array}{c}\text { Skill } \\
10\end{array}$ & $\begin{array}{c}\text { Skill } \\
11\end{array}$ \\
\hline Task 1 & 4 & 5 & 3 & 5 & 3 & 2 & 5 & 4 & 3 & 4 & 5 \\
\hline Task 2 & 2 & 2 & 2 & 5 & 4 & 3 & 1 & 3 & 1 & 3 & 1 \\
\hline Task 3 & 3 & 4 & 3 & 4 & 2 & 5 & 2 & 3 & 5 & 4 & 3 \\
\hline Task 4 & 2 & 4 & 2 & 2 & 5 & 3 & 5 & 2 & 4 & 5 & 2 \\
\hline Task 5 & 5 & 2 & 5 & 4 & 5 & 3 & 1 & 4 & 5 & 5 & 4 \\
\hline Task 6 & 5 & 2 & 3 & 3 & 4 & 3 & 2 & 4 & 3 & 2 & 2 \\
\hline Task 7 & 2 & 1 & 5 & 5 & 1 & 5 & 4 & 4 & 2 & 1 & 5 \\
\hline Task 8 & 2 & 4 & 5 & 3 & 1 & 2 & 5 & 3 & 3 & 2 & 4 \\
\hline Task 9 & 2 & 2 & 3 & 4 & 1 & 1 & 3 & 5 & 1 & 4 & 4 \\
\hline Task 10 & 3 & 2 & 4 & 2 & 1 & 3 & 4 & 4 & 4 & 4 & 2 \\
\hline Task 11 & 1 & 2 & 1 & 5 & 1 & 5 & 2 & 1 & 1 & 3 & 1 \\
\hline Task 12 & 5 & 4 & 4 & 2 & 2 & 1 & 1 & 5 & 1 & 2 & 3 \\
\hline Task 13 & 1 & 5 & 2 & 3 & 1 & 2 & 5 & 5 & 2 & 1 & 1 \\
\hline
\end{tabular}

The above matrix shows the required skill levels for each task and skill type. 


\begin{tabular}{|c|c|}
\cline { 2 - 2 } \multicolumn{1}{c|}{} & $\begin{array}{c}\text { Task } \\
\text { Time }\end{array}$ \\
\hline Task 1 & 4 \\
\hline Task 2 & 4 \\
\hline Task 3 & 4 \\
\hline Task 4 & 4 \\
\hline Task 5 & 4 \\
\hline Task 6 & 4 \\
\hline Task 7 & 4 \\
\hline Task 8 & 4 \\
\hline Task 9 & 4 \\
\hline Task 10 & 4 \\
\hline Task 11 & 4 \\
\hline Task 12 & 4 \\
\hline Task 13 & 4 \\
\hline
\end{tabular}

\begin{tabular}{|c|c|}
\cline { 2 - 2 } \multicolumn{1}{c|}{} & $\begin{array}{c}\text { Worker } \\
\text { Capacity }\end{array}$ \\
\hline Worker 1 & 25 \\
\hline Worker 2 & 25 \\
\hline Worker 3 & 25 \\
\hline Worker 4 & 25 \\
\hline Worker 5 & 25 \\
\hline Worker 6 & 25 \\
\hline Worker 7 & 25 \\
\hline Worker 8 & 25 \\
\hline Worker 9 & 25 \\
\hline
\end{tabular}

\begin{tabular}{|c|c|c|c|c|c|}
\hline $\begin{array}{c}\text { Cost to } \\
\text { Train Matrix }\end{array}$ & \multicolumn{5}{|c|}{} \\
\cline { 1 - 4 } & $\begin{array}{c}\text { Train to } \\
\text { Skill } \\
\text { Level 1 }\end{array}$ & $\begin{array}{c}\text { Train to } \\
\text { Skill } \\
\text { Level 2 }\end{array}$ & $\begin{array}{c}\text { Train to } \\
\text { Skill } \\
\text { Level 3 }\end{array}$ & $\begin{array}{c}\text { Train to } \\
\text { Skill } \\
\text { Level 4 }\end{array}$ & $\begin{array}{c}\text { Train to } \\
\text { Skill } \\
\text { Level 5 }\end{array}$ \\
\hline Skill 1 & 0 & 1 & 3 & 7 & 15 \\
\hline Skill 2 & 0 & 1 & 3 & 7 & 15 \\
\hline Skill 3 & 0 & 1 & 3 & 7 & 15 \\
\hline Skill 4 & 0 & 1 & 3 & 7 & 15 \\
\hline Skill 5 & 0 & 1 & 3 & 7 & 15 \\
\hline Skill 6 & 0 & 1 & 3 & 7 & 15 \\
\hline Skill 7 & 0 & 1 & 3 & 7 & 15 \\
\hline Skill 8 & 0 & 1 & 3 & 7 & 15 \\
\hline Skill 9 & 0 & 1 & 3 & 7 & 15 \\
\hline Skill 10 & 0 & 1 & 3 & 7 & 15 \\
\hline Skill 11 & 0 & 1 & 3 & 7 & 15 \\
\hline
\end{tabular}


The above matrix shows the cost to train a worker up to a skill level from the level immediately preceding it for each skill type. This sample model assumes that the cost to train up to the higher skill levels is not liner. In other words, it costs more to train a worker from a skill level of 4 to 5 than from a skill level of 1 to 2 .

\begin{tabular}{|c|c|c|c|c|c|}
\hline \multirow{2}{*}{$\begin{array}{c}\text { Time to } \\
\text { Train Matrix }\end{array}$} & & & & & \\
\hline & $\begin{array}{c}\text { Train to } \\
\text { Skill } \\
\text { Level } 1\end{array}$ & $\begin{array}{c}\text { Train to } \\
\text { Skill } \\
\text { Level } 2\end{array}$ & $\begin{array}{c}\text { Train to } \\
\text { Skill } \\
\text { Level } 3\end{array}$ & $\begin{array}{c}\text { Train to } \\
\text { Skill } \\
\text { Level } 4\end{array}$ & $\begin{array}{c}\text { Train to } \\
\text { Skill } \\
\text { Level } 5\end{array}$ \\
\hline Skill 1 & 0 & 1 & 1 & 1 & 1 \\
\hline Skill 2 & 0 & 1 & 1 & 1 & 1 \\
\hline Skill 3 & 0 & 1 & 1 & 1 & 1 \\
\hline Skill 4 & 0 & 1 & 1 & 1 & 1 \\
\hline Skill 5 & 0 & 1 & 1 & 1 & 1 \\
\hline Skill 6 & 0 & 1 & 1 & 1 & 1 \\
\hline Skill 7 & 0 & 1 & 1 & 1 & 1 \\
\hline Skill 8 & 0 & 1 & 1 & 1 & 1 \\
\hline Skill 9 & 0 & 1 & 1 & 1 & 1 \\
\hline Skill 10 & 0 & 1 & 1 & 1 & 1 \\
\hline Skill 11 & 0 & 1 & 1 & 1 & 1 \\
\hline
\end{tabular}

The above matrix shows the time to train a worker up to a skill level from the level immediately preceding it for each skill type. 


\section{APPENDIX B}

TEST DATASET 2

\begin{tabular}{|c|c|}
\hline Number of workers & 9 \\
\hline Number of skills & 11 \\
\hline Number of tasks & 13 \\
\hline
\end{tabular}

\begin{tabular}{|c|c|c|c|c|c|c|c|c|c|c|c|}
\hline $\begin{array}{c}\text { Worker Skill } \\
\text { Matrix }\end{array}$ & & & & & & & & & & & \\
\hline & $\begin{array}{c}\text { Skill } \\
1\end{array}$ & $\begin{array}{c}\text { Skill } \\
2\end{array}$ & $\begin{array}{c}\text { Skill } \\
3\end{array}$ & $\begin{array}{c}\text { Skill } \\
4\end{array}$ & $\begin{array}{c}\text { Skill } \\
5\end{array}$ & $\begin{array}{c}\text { Skill } \\
6\end{array}$ & $\begin{array}{c}\text { Skill } \\
7\end{array}$ & $\begin{array}{c}\text { Skill } \\
8\end{array}$ & $\begin{array}{c}\text { Skill } \\
9\end{array}$ & $\begin{array}{c}\text { Skill } \\
10\end{array}$ & $\begin{array}{c}\text { Skill } \\
11\end{array}$ \\
\hline Worker 1 & 2 & 2 & 3 & 4 & 4 & 1 & 5 & 3 & 4 & 2 & 1 \\
\hline Worker 2 & 5 & 2 & 1 & 3 & 2 & 5 & 1 & 4 & 2 & 5 & 2 \\
\hline Worker 3 & 4 & 2 & 3 & 2 & 4 & 2 & 2 & 1 & 3 & 4 & 4 \\
\hline Worker 4 & 1 & 2 & 5 & 5 & 1 & 2 & 5 & 2 & 3 & 3 & 2 \\
\hline Worker 5 & 2 & 2 & 2 & 2 & 1 & 3 & 2 & 3 & 4 & 4 & 2 \\
\hline Worker 6 & 1 & 2 & 1 & 2 & 5 & 2 & 2 & 2 & 3 & 3 & 3 \\
\hline Worker 7 & 4 & 1 & 3 & 2 & 4 & 4 & 2 & 2 & 1 & 2 & 2 \\
\hline Worker 8 & 2 & 5 & 2 & 5 & 3 & 4 & 4 & 5 & 2 & 2 & 3 \\
\hline Worker 9 & 2 & 2 & 2 & 4 & 4 & 1 & 1 & 5 & 2 & 3 & 3 \\
\hline
\end{tabular}

The above matrix shows the current skill levels of each worker for each skill type.

\begin{tabular}{|c|c|c|c|c|c|c|c|c|c|c|c|}
$\begin{array}{c}\text { Task Skill } \\
\text { Matrix }\end{array}$ & \multicolumn{10}{|c|}{} \\
& $\begin{array}{c}\text { Skill } \\
1\end{array}$ & $\begin{array}{c}\text { Skill } \\
2\end{array}$ & $\begin{array}{c}\text { Skill } \\
3\end{array}$ & $\begin{array}{c}\text { Skill } \\
4\end{array}$ & $\begin{array}{c}\text { Skill } \\
5\end{array}$ & $\begin{array}{c}\text { Skill } \\
6\end{array}$ & $\begin{array}{c}\text { Skill } \\
7\end{array}$ & $\begin{array}{c}\text { Skill } \\
8\end{array}$ & $\begin{array}{c}\text { Skill } \\
9\end{array}$ & $\begin{array}{c}\text { Skill } \\
10\end{array}$ & $\begin{array}{c}\text { Skill } \\
11\end{array}$ \\
\hline Task 1 & 2 & 3 & 5 & 2 & 2 & 2 & 3 & 5 & 3 & 1 & 3 \\
\hline Task 2 & 1 & 4 & 2 & 4 & 4 & 1 & 3 & 2 & 5 & 3 & 1 \\
\hline Task 3 & 2 & 4 & 3 & 5 & 4 & 2 & 5 & 4 & 2 & 3 & 2 \\
\hline Task 4 & 1 & 1 & 3 & 4 & 5 & 5 & 1 & 1 & 2 & 1 & 4 \\
\hline Task 5 & 3 & 4 & 3 & 4 & 1 & 5 & 3 & 3 & 1 & 1 & 1 \\
\hline Task 6 & 5 & 1 & 3 & 1 & 4 & 5 & 1 & 4 & 2 & 1 & 1 \\
\hline Task 7 & 1 & 2 & 2 & 5 & 3 & 1 & 2 & 2 & 2 & 1 & 2 \\
\hline Task 8 & 5 & 2 & 5 & 5 & 4 & 5 & 5 & 5 & 3 & 2 & 3 \\
\hline Task 9 & 4 & 2 & 4 & 2 & 3 & 1 & 1 & 3 & 1 & 4 & 5 \\
\hline Task 10 & 4 & 5 & 5 & 4 & 5 & 2 & 5 & 3 & 1 & 1 & 2 \\
\hline Task 11 & 1 & 4 & 5 & 4 & 3 & 4 & 2 & 3 & 1 & 4 & 1 \\
\hline Task 12 & 1 & 3 & 1 & 1 & 4 & 3 & 2 & 1 & 1 & 5 & 2 \\
\hline Task 13 & 1 & 2 & 2 & 5 & 4 & 1 & 3 & 1 & 2 & 2 & 5 \\
\hline
\end{tabular}

The above matrix shows the required skill levels for each task and skill type. 


\begin{tabular}{|c|c|}
\cline { 2 - 2 } \multicolumn{1}{c|}{} & $\begin{array}{c}\text { Task } \\
\text { Time }\end{array}$ \\
\hline Task 1 & 4 \\
\hline Task 2 & 4 \\
\hline Task 3 & 4 \\
\hline Task 4 & 4 \\
\hline Task 5 & 4 \\
\hline Task 6 & 4 \\
\hline Task 7 & 4 \\
\hline Task 8 & 4 \\
\hline Task 9 & 4 \\
\hline Task 10 & 4 \\
\hline Task 11 & 4 \\
\hline Task 12 & 4 \\
\hline Task 13 & 4 \\
\hline
\end{tabular}

\begin{tabular}{|c|c|}
\cline { 2 - 2 } \multicolumn{1}{c|}{} & $\begin{array}{c}\text { Worker } \\
\text { Capacity }\end{array}$ \\
\hline Worker 1 & 25 \\
\hline Worker 2 & 25 \\
\hline Worker 3 & 25 \\
\hline Worker 4 & 25 \\
\hline Worker 5 & 25 \\
\hline Worker 6 & 25 \\
\hline Worker 7 & 25 \\
\hline Worker 8 & 25 \\
\hline Worker 9 & 25 \\
\hline
\end{tabular}

\begin{tabular}{|c|c|c|c|c|c|}
\hline $\begin{array}{c}\text { Cost to } \\
\text { Train Matrix }\end{array}$ & \multicolumn{5}{|c|}{} \\
\cline { 1 - 4 } & $\begin{array}{c}\text { Train to } \\
\text { Skill } \\
\text { Level 1 }\end{array}$ & $\begin{array}{c}\text { Train to } \\
\text { Skill } \\
\text { Level 2 }\end{array}$ & $\begin{array}{c}\text { Train to } \\
\text { Skill } \\
\text { Level 3 }\end{array}$ & $\begin{array}{c}\text { Train to } \\
\text { Skill } \\
\text { Level 4 }\end{array}$ & $\begin{array}{c}\text { Train to } \\
\text { Skill } \\
\text { Level 5 }\end{array}$ \\
\hline Skill 1 & 0 & 1 & 3 & 7 & 15 \\
\hline Skill 2 & 0 & 1 & 3 & 7 & 15 \\
\hline Skill 3 & 0 & 1 & 3 & 7 & 15 \\
\hline Skill 4 & 0 & 1 & 3 & 7 & 15 \\
\hline Skill 5 & 0 & 1 & 3 & 7 & 15 \\
\hline Skill 6 & 0 & 1 & 3 & 7 & 15 \\
\hline Skill 7 & 0 & 1 & 3 & 7 & 15 \\
\hline Skill 8 & 0 & 1 & 3 & 7 & 15 \\
\hline Skill 9 & 0 & 1 & 3 & 7 & 15 \\
\hline Skill 10 & 0 & 1 & 3 & 7 & 15 \\
\hline Skill 11 & 0 & 1 & 3 & 7 & 15 \\
\hline
\end{tabular}


The above matrix shows the cost to train a worker up to a skill level from the level immediately preceding it for each skill type. This sample model assumes that the cost to train up to the higher skill levels is not liner. In other words, it costs more to train a worker from a skill level of 4 to 5 than from a skill level of 1 to 2 .

\begin{tabular}{|c|c|c|c|c|c|}
\hline \multirow{2}{*}{$\begin{array}{c}\text { Time to } \\
\text { Train Matrix }\end{array}$} & & & & & \\
\hline & $\begin{array}{c}\text { Train to } \\
\text { Skill } \\
\text { Level } 1\end{array}$ & $\begin{array}{c}\text { Train to } \\
\text { Skill } \\
\text { Level } 2\end{array}$ & $\begin{array}{c}\text { Train to } \\
\text { Skill } \\
\text { Level } 3\end{array}$ & $\begin{array}{c}\text { Train to } \\
\text { Skill } \\
\text { Level } 4\end{array}$ & $\begin{array}{c}\text { Train to } \\
\text { Skill } \\
\text { Level } 5\end{array}$ \\
\hline Skill 1 & 0 & 1 & 1 & 1 & 1 \\
\hline Skill 2 & 0 & 1 & 1 & 1 & 1 \\
\hline Skill 3 & 0 & 1 & 1 & 1 & 1 \\
\hline Skill 4 & 0 & 1 & 1 & 1 & 1 \\
\hline Skill 5 & 0 & 1 & 1 & 1 & 1 \\
\hline Skill 6 & 0 & 1 & 1 & 1 & 1 \\
\hline Skill 7 & 0 & 1 & 1 & 1 & 1 \\
\hline Skill 8 & 0 & 1 & 1 & 1 & 1 \\
\hline Skill 9 & 0 & 1 & 1 & 1 & 1 \\
\hline Skill 10 & 0 & 1 & 1 & 1 & 1 \\
\hline Skill 11 & 0 & 1 & 1 & 1 & 1 \\
\hline
\end{tabular}

The above matrix shows the time to train a worker up to a skill level from the level immediately preceding it for each skill type. 


\section{APPENDIX C}

\section{TEST DATASET 3}

\begin{tabular}{|c|c|}
\hline Number of workers & 9 \\
\hline Number of skills & 11 \\
\hline Number of tasks & 13 \\
\hline
\end{tabular}

\begin{tabular}{|c|c|c|c|c|c|c|c|c|c|c|c|}
\hline $\begin{array}{l}\text { Worker Skill } \\
\text { Matrix }\end{array}$ & & & & & & & & & & & \\
\hline & $\begin{array}{c}\text { Skill } \\
1\end{array}$ & $\begin{array}{c}\text { Skill } \\
2\end{array}$ & $\begin{array}{c}\text { Skill } \\
3\end{array}$ & $\begin{array}{c}\text { Skill } \\
4\end{array}$ & $\begin{array}{c}\text { Skill } \\
5\end{array}$ & $\begin{array}{c}\text { Skill } \\
6\end{array}$ & $\begin{array}{c}\text { Skill } \\
7\end{array}$ & $\begin{array}{c}\text { Skill } \\
8\end{array}$ & $\begin{array}{c}\text { Skill } \\
9\end{array}$ & $\begin{array}{c}\text { Skill } \\
10\end{array}$ & $\begin{array}{c}\text { Skill } \\
11\end{array}$ \\
\hline Worker 1 & 5 & 3 & 3 & 4 & 1 & 5 & 5 & 2 & 4 & 4 & 4 \\
\hline Worker 2 & 2 & 5 & 3 & 3 & 1 & 3 & 1 & 1 & 5 & 5 & 2 \\
\hline Worker 3 & 1 & 5 & 5 & 4 & 5 & 5 & 4 & 4 & 5 & 1 & 5 \\
\hline Worker 4 & 2 & 3 & 1 & 1 & 2 & 4 & 4 & 3 & 4 & 1 & 3 \\
\hline Worker 5 & 3 & 3 & 2 & 1 & 1 & 4 & 5 & 2 & 3 & 2 & 3 \\
\hline Worker 6 & 2 & 1 & 5 & 5 & 4 & 2 & 4 & 5 & 4 & 1 & 1 \\
\hline Worker 7 & 5 & 4 & 1 & 3 & 4 & 3 & 3 & 3 & 4 & 4 & 1 \\
\hline Worker 8 & 2 & 2 & 5 & 4 & 2 & 2 & 5 & 5 & 3 & 4 & 4 \\
\hline Worker 9 & 3 & 2 & 5 & 5 & 1 & 3 & 1 & 3 & 2 & 1 & 5 \\
\hline
\end{tabular}

The above matrix shows the current skill levels of each worker for each skill type.

\begin{tabular}{|c|c|c|c|c|c|c|c|c|c|c|c|}
\hline $\begin{array}{l}\text { Task Skill } \\
\text { Matrix }\end{array}$ & & & & & & & & & & & \\
\hline & $\begin{array}{c}\text { Skill } \\
1\end{array}$ & $\begin{array}{c}\text { Skill } \\
2\end{array}$ & $\begin{array}{c}\text { Skill } \\
3\end{array}$ & $\begin{array}{c}\text { Skill } \\
4\end{array}$ & $\begin{array}{c}\text { Skill } \\
5\end{array}$ & $\begin{array}{c}\text { Skill } \\
6\end{array}$ & $\begin{array}{c}\text { Skill } \\
7\end{array}$ & $\begin{array}{c}\text { Skill } \\
8\end{array}$ & $\begin{array}{c}\text { Skill } \\
9\end{array}$ & $\begin{array}{c}\text { Skill } \\
10\end{array}$ & $\begin{array}{c}\text { Skill } \\
11\end{array}$ \\
\hline Task 1 & 5 & 2 & 3 & 3 & 4 & 4 & 5 & 5 & 2 & 3 & 5 \\
\hline Task 2 & 2 & 2 & 4 & 3 & 5 & 5 & 3 & 2 & 4 & 5 & 2 \\
\hline Task 3 & 1 & 4 & 3 & 4 & 3 & 3 & 5 & 3 & 2 & 3 & 2 \\
\hline Task 4 & 1 & 1 & 5 & 2 & 1 & 3 & 1 & 5 & 1 & 1 & 3 \\
\hline Task 5 & 3 & 3 & 4 & 5 & 1 & 4 & 2 & 5 & 4 & 3 & 3 \\
\hline Task 6 & 1 & 3 & 5 & 1 & 3 & 3 & 5 & 1 & 4 & 1 & 3 \\
\hline Task 7 & 5 & 1 & 1 & 1 & 5 & 5 & 2 & 4 & 4 & 3 & 4 \\
\hline Task 8 & 3 & 2 & 1 & 1 & 2 & 2 & 2 & 1 & 2 & 4 & 5 \\
\hline Task 9 & 2 & 5 & 5 & 1 & 2 & 2 & 1 & 4 & 4 & 3 & 5 \\
\hline Task 10 & 5 & 5 & 2 & 5 & 4 & 5 & 3 & 5 & 4 & 3 & 5 \\
\hline Task 11 & 4 & 1 & 1 & 1 & 2 & 2 & 3 & 3 & 5 & 2 & 5 \\
\hline Task 12 & 1 & 3 & 1 & 4 & 5 & 5 & 1 & 2 & 5 & 5 & 5 \\
\hline Task 13 & 3 & 1 & 1 & 4 & 4 & 3 & 1 & 2 & 4 & 4 & 1 \\
\hline
\end{tabular}

The above matrix shows the required skill levels for each task and skill type. 


\begin{tabular}{|c|c|}
\cline { 2 - 2 } \multicolumn{1}{c|}{} & $\begin{array}{c}\text { Task } \\
\text { Time }\end{array}$ \\
\hline Task 1 & 4 \\
\hline Task 2 & 4 \\
\hline Task 3 & 4 \\
\hline Task 4 & 4 \\
\hline Task 5 & 4 \\
\hline Task 6 & 4 \\
\hline Task 7 & 4 \\
\hline Task 8 & 4 \\
\hline Task 9 & 4 \\
\hline Task 10 & 4 \\
\hline Task 11 & 4 \\
\hline Task 12 & 4 \\
\hline Task 13 & 4 \\
\hline
\end{tabular}

\begin{tabular}{|c|c|}
\cline { 2 - 2 } \multicolumn{1}{c|}{} & $\begin{array}{c}\text { Worker } \\
\text { Capacity }\end{array}$ \\
\hline Worker 1 & 25 \\
\hline Worker 2 & 25 \\
\hline Worker 3 & 25 \\
\hline Worker 4 & 25 \\
\hline Worker 5 & 25 \\
\hline Worker 6 & 25 \\
\hline Worker 7 & 25 \\
\hline Worker 8 & 25 \\
\hline Worker 9 & 25 \\
\hline
\end{tabular}

\begin{tabular}{|c|c|c|c|c|c|}
\hline $\begin{array}{c}\text { Cost to } \\
\text { Train Matrix }\end{array}$ & \multicolumn{5}{|c|}{} \\
\cline { 1 - 4 } & $\begin{array}{c}\text { Train to } \\
\text { Skill } \\
\text { Level 1 }\end{array}$ & $\begin{array}{c}\text { Train to } \\
\text { Skill } \\
\text { Level 2 }\end{array}$ & $\begin{array}{c}\text { Train to } \\
\text { Skill } \\
\text { Level 3 }\end{array}$ & $\begin{array}{c}\text { Train to } \\
\text { Skill } \\
\text { Level 4 }\end{array}$ & $\begin{array}{c}\text { Train to } \\
\text { Skill } \\
\text { Level 5 }\end{array}$ \\
\hline Skill 1 & 0 & 1 & 3 & 7 & 15 \\
\hline Skill 2 & 0 & 1 & 3 & 7 & 15 \\
\hline Skill 3 & 0 & 1 & 3 & 7 & 15 \\
\hline Skill 4 & 0 & 1 & 3 & 7 & 15 \\
\hline Skill 5 & 0 & 1 & 3 & 7 & 15 \\
\hline Skill 6 & 0 & 1 & 3 & 7 & 15 \\
\hline Skill 7 & 0 & 1 & 3 & 7 & 15 \\
\hline Skill 8 & 0 & 1 & 3 & 7 & 15 \\
\hline Skill 9 & 0 & 1 & 3 & 7 & 15 \\
\hline Skill 10 & 0 & 1 & 3 & 7 & 15 \\
\hline Skill 11 & 0 & 1 & 3 & 7 & 15 \\
\hline
\end{tabular}


The above matrix shows the cost to train a worker up to a skill level from the level immediately preceding it for each skill type. This sample model assumes that the cost to train up to the higher skill levels is not liner. In other words, it costs more to train a worker from a skill level of 4 to 5 than from a skill level of 1 to 2 .

\begin{tabular}{|c|c|c|c|c|c|}
\hline \multirow{2}{*}{$\begin{array}{c}\text { Time to } \\
\text { Train Matrix }\end{array}$} & & & & & \\
\hline & $\begin{array}{c}\text { Train to } \\
\text { Skill } \\
\text { Level } 1\end{array}$ & $\begin{array}{c}\text { Train to } \\
\text { Skill } \\
\text { Level } 2\end{array}$ & $\begin{array}{c}\text { Train to } \\
\text { Skill } \\
\text { Level } 3\end{array}$ & $\begin{array}{c}\text { Train to } \\
\text { Skill } \\
\text { Level } 4\end{array}$ & $\begin{array}{c}\text { Train to } \\
\text { Skill } \\
\text { Level } 5\end{array}$ \\
\hline Skill 1 & 0 & 1 & 1 & 1 & 1 \\
\hline Skill 2 & 0 & 1 & 1 & 1 & 1 \\
\hline Skill 3 & 0 & 1 & 1 & 1 & 1 \\
\hline Skill 4 & 0 & 1 & 1 & 1 & 1 \\
\hline Skill 5 & 0 & 1 & 1 & 1 & 1 \\
\hline Skill 6 & 0 & 1 & 1 & 1 & 1 \\
\hline Skill 7 & 0 & 1 & 1 & 1 & 1 \\
\hline Skill 8 & 0 & 1 & 1 & 1 & 1 \\
\hline Skill 9 & 0 & 1 & 1 & 1 & 1 \\
\hline Skill 10 & 0 & 1 & 1 & 1 & 1 \\
\hline Skill 11 & 0 & 1 & 1 & 1 & 1 \\
\hline
\end{tabular}

The above matrix shows the time to train a worker up to a skill level from the level immediately preceding it for each skill type. 


\section{APPENDIX D}

\section{CODE FOR CREATING INPUT SHEET}

Sub inputs()

Dim numworkers As Single

Dim numskills As Single

Dim numtasks As Single

Sheets("Input").Select

numworkers = Application.InputBox("Input number of workers", "")

numskills = Application.InputBox("Input number of skills", "")

numtasks = Application.InputBox("Input number of tasks", "')

'Insert values

ActiveSheet.Cells $(1,1)$. Value = "Number of workers"

ActiveSheet.Cells $(2,1)$.Value $=$ "Number of skills"

ActiveSheet.Cells $(3,1)$.Value $=$ "Number of tasks"

ActiveSheet.Cells $(1,2)$.Value $=$ numworkers

ActiveSheet.Cells (2, 2). Value $=$ numskills

ActiveSheet.Cells $(3,2)$.Value $=$ numtasks

'Create Worker Skill Matrix

For $\mathrm{i}=1$ To numworkers

For $\mathrm{k}=1$ To numskills

ActiveSheet.Cells $(5,1)$. Value = "Worker Skill Matrix"

ActiveSheet.Cells $(i+6,1)$. Value $=$ "Worker " \& i

ActiveSheet.Cells $(6, \mathrm{k}+1)$. Value $=$ "Skill " \& k

Next k

Next i

'Create Task Skill Matrix

For $\mathrm{j}=1$ To numtasks

For $\mathrm{k}=1$ To numskills

ActiveSheet.Cells $(8+$ numworkers, 1).Value = "Task Skill Matrix"

ActiveSheet.Cells $(9+$ numworkers $+\mathrm{j}, 1)$. Value $=$ "Task " \& j

ActiveSheet.Cells $(9+$ numworkers, $\mathrm{k}+1)$.Value $=$ "Skill " \& k

Next k

Next j

'Create Task Time Matrix

For $\mathrm{j}=1$ To numtasks

ActiveSheet.Cells(11 + numtasks + numworkers, 2).Value = "Task Time"

ActiveSheet.Cells $(11+$ numtasks + numworkers $+\mathrm{j}, 1) \cdot$ Value $=$ "Task $" \& \mathrm{j}$ 
Next j

'Create Worker Capacity Matrix

For $\mathrm{i}=1$ To numworkers

ActiveSheet.Cells $(13+2 *$ numtasks + numworkers, 2$)$. Value $=$ "Worker Capacity"

ActiveSheet.Cells $(13+2 *$ numtasks + numworkers $+\mathrm{i}, 1)$. Value $=$ "Worker " \& $\mathrm{i}$

Next i

'Create Training Cost Matrix

For $\mathrm{i}=1$ To numskills

For $\mathrm{j}=1$ To 5

ActiveSheet.Cells $(15+2 *$ numtasks $+2 *$ numworkers, 1$)$. Value $=$ "Cost to Train Matrix"

ActiveSheet.Cells $(16+2 *$ numtasks $+2 *$ numworkers $+\mathrm{i}, 1)$.Value $=$ "Skill " $\& \mathrm{i}$

ActiveSheet.Cells $(16+2 *$ numtasks $+2 *$ numworkers, $1+\mathrm{j})$.Value $=$ "Train to

Skill Level " \& j

Next j

Next i

'Create Training Time Matrix

For $\mathrm{i}=1$ To numskills

For $\mathrm{j}=1$ To 5

ActiveSheet.Cells $(18+2 *$ numtasks $+2 *$ numworkers + numskills, 1$)$. Value $=$

"Time to Train Matrix"

ActiveSheet.Cells $(19+2 *$ numtasks $+2 *$ numworkers + numskills $+\mathrm{i}, 1) \cdot$ Value $=$ "Skill " \& i

ActiveSheet.Cells $(19+2 *$ numtasks $+2 *$ numworkers + numskills, $1+\mathrm{j}) \cdot$ Value $=$ "Train to Skill Level " \& j

Next $j$

Next i

'Create Skill Name Matrix

For $\mathrm{i}=1$ To numskills

ActiveSheet.Cells $(19+2 *$ numtasks $+2 *$ numworkers + numskills + numskills +2 , 1) = "Skill"

ActiveSheet.Cells $(19+2 *$ numtasks $+2 *$ numworkers + numskills + numskills +2 ,

2) = "Skill Name"

ActiveSheet.Cells $(19+2 *$ numtasks $+2 *$ numworkers + numskills + numskills $+2+$ $\mathrm{i}, 1)=\mathrm{i}$

Next i

'Create Worker Name Matrix

For $\mathrm{i}=1$ To numworkers

ActiveSheet.Cells $(19+2 *$ numtasks $+2 *$ numworkers + numskills + numskills $+2+$ numskills $+2,1)=$ "Worker " 
ActiveSheet.Cells $(19+2 *$ numtasks $+2 *$ numworkers + numskills + numskills $+2+$ numskills $+2,2)=$ "Worker Name"

ActiveSheet.Cells $(19+2 *$ numtasks $+2 *$ numworkers + numskills + numskills $+2+$ numskills $+2+\mathrm{i}, 1)=\mathrm{i}$

Next i

'Create Task Name Matrix

For $\mathrm{i}=1$ To numtasks

ActiveSheet.Cells $(19+2 *$ numtasks $+2 *$ numworkers + numskills + numskills $+2+$ numskills $+2+$ numworkers $+2,1)=$ "Task"

ActiveSheet.Cells $(19+2 *$ numtasks $+2 *$ numworkers + numskills + numskills $+2+$ numskills $+2+$ numworkers $+2,2)=$ "Task Name"

ActiveSheet.Cells $(19+2 *$ numtasks $+2 *$ numworkers + numskills + numskills $+2+$ numskills $+2+$ numworkers $+2+\mathrm{i}, 1)=\mathrm{i}$

Next i

End Sub 


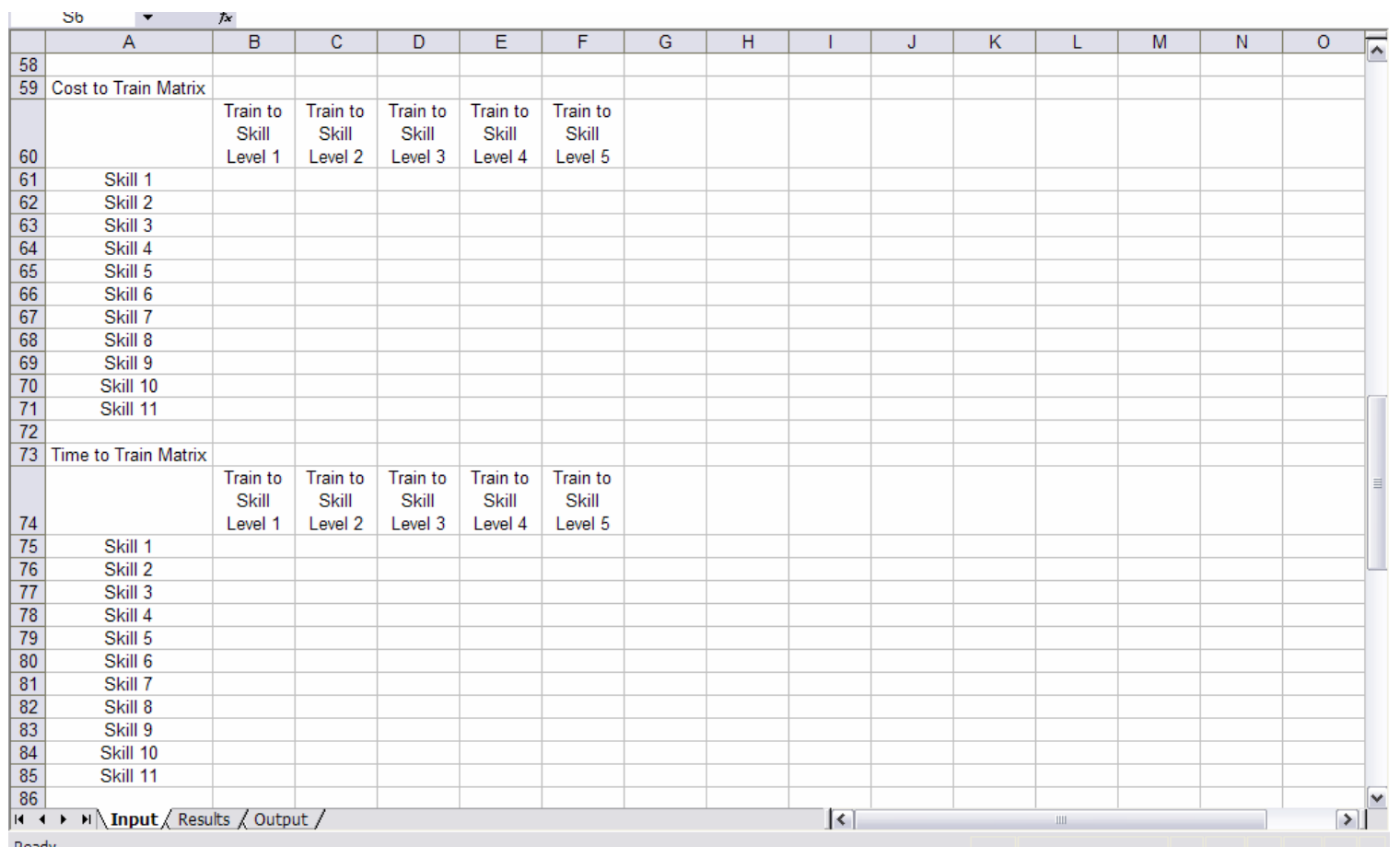

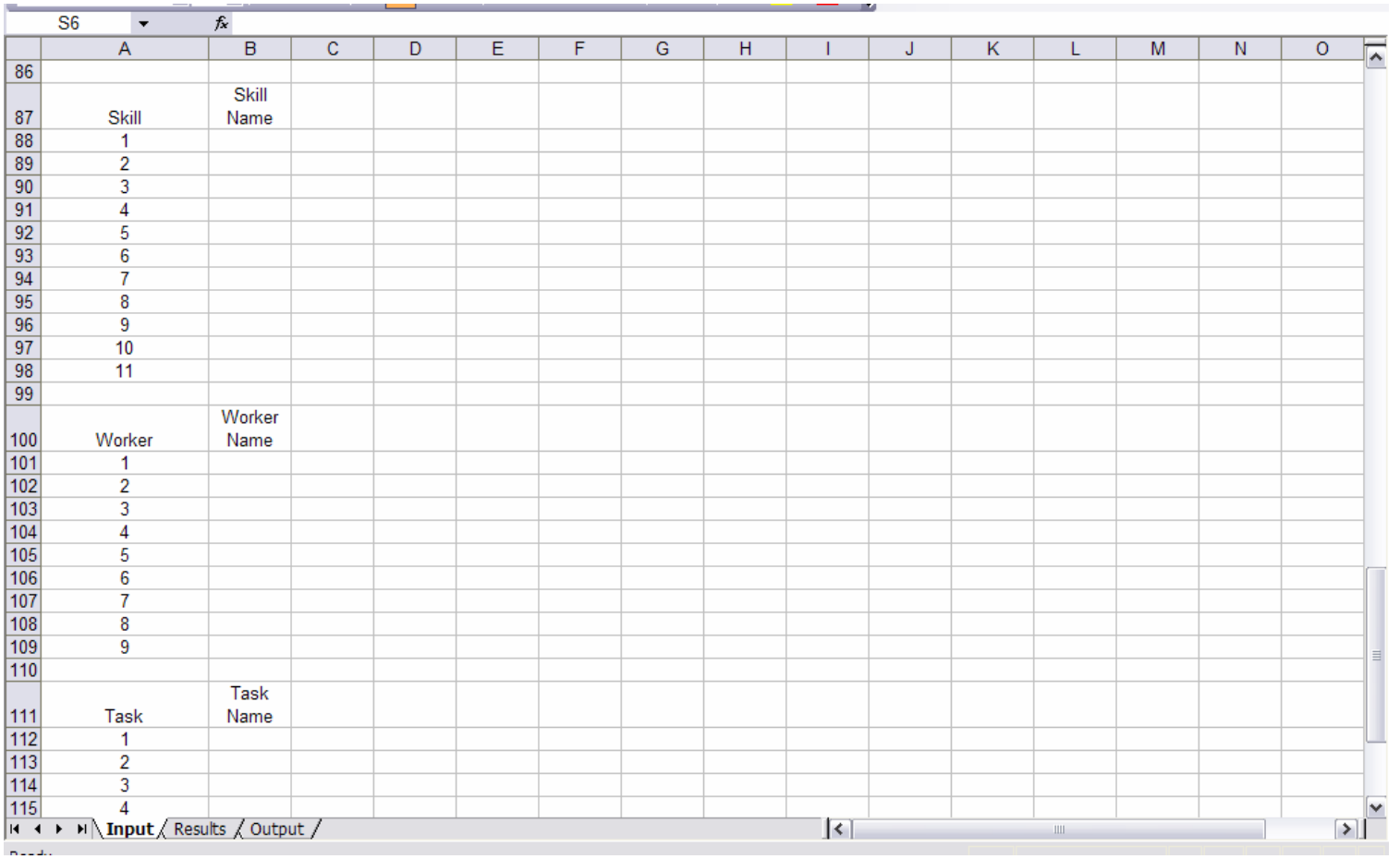




\begin{tabular}{|c|c|c|c|c|c|c|c|c|c|c|c|c|c|c|c|}
\hline & A & & & & & & & & & & & & & & \\
\hline \multicolumn{16}{|l|}{110} \\
\hline 111 & Task & Name & & & & & & & & & & & & & \\
\hline 112 & 1 & & & & & & & & & & & & & & \\
\hline 113 & 2 & & & & & & & & & & & & & & \\
\hline 114 & 3 & & & & & & & & & & & & & & \\
\hline 115 & 4 & & & & & & & & & & & & & & \\
\hline 116 & 5 & & & & & & & & & & & & & & \\
\hline 117 & 6 & & & & & & & & & & & & & & \\
\hline 118 & 7 & & & & & & & & & & & & & & \\
\hline 119 & 8 & & & & & & & & & & & & & & \\
\hline 120 & 9 & & & & & & & & & & & & & & \\
\hline 121 & 10 & & & & & & & & & & & & & & \\
\hline 122 & 11 & & & & & & & & & & & & & & \\
\hline 123 & 12 & & & & & & & & & & & & & & \\
\hline 124 & 13 & & & & & & & & & & & & & & \\
\hline \multirow{2}{*}{\multicolumn{16}{|c|}{$\begin{array}{l}125 \\
126 \\
1\end{array}$}} \\
\hline & & & & & & & & & & & & & & & \\
\hline \multicolumn{16}{|l|}{127} \\
\hline \multicolumn{16}{|l|}{128} \\
\hline \multicolumn{16}{|l|}{129} \\
\hline \multirow{2}{*}{\multicolumn{16}{|c|}{\begin{tabular}{|l|}
130 \\
131
\end{tabular}}} \\
\hline & & & & & & & & & & & & & & & \\
\hline \multirow{2}{*}{\multicolumn{16}{|c|}{\begin{tabular}{|l|l|}
133 \\
\end{tabular}}} \\
\hline & & & & & & & & & & & & & & & \\
\hline \multicolumn{16}{|l|}{134} \\
\hline \multirow{2}{*}{\multicolumn{16}{|c|}{$\begin{array}{l}135 \\
136\end{array}$}} \\
\hline \multirow{2}{*}{\multicolumn{11}{|c|}{136}} & & & & & \\
\hline \multirow{2}{*}{\multicolumn{15}{|c|}{\begin{tabular}{|l|}
137 \\
138
\end{tabular}}} & \\
\hline \multirow{2}{*}{\multicolumn{16}{|c|}{$\mid$}} \\
\hline & & & & & & & & & & & & & & & \\
\hline \multicolumn{16}{|l|}{140} \\
\hline 141 & יוסק & Soutp & & & & & & & & & & & & & \\
\hline
\end{tabular}




\section{APPENDIX F}

\section{CODE FOR MODIFIED GREEDY ALGORITHM}

Public Sub heuristic()

Dim workerskill() As Single, oworkerskill() As Single

Dim taskskill() As Single, otaskskill() As Single

Dim tasktime() As Single, otasktime() As Single

Dim workercapacity() As Single, oworkercapacity() As Single

Dim traincost() As Single, otraincost() As Single

Dim traintime() As Single, otraintime() As Single

Dim workerassign() As Single

Dim workertaskcost() As Single, oworkertaskcost() As Single

Dim workertasktime() As Single, oworkertasktime() As Single

Dim taskassigned() As Single

Dim tcost() As Single

Dim ttime() As Single

Dim available() As Single

Dim bestworkerassign() As Single

Dim numworkers As Single, numskills As Single, numtasks As Single

Dim totaltaskcost() As Single

Dim totalworkercost() As Single

Dim workerphase1() As Single

Dim cellrow As Single

perprior $=20$

perrestrict $=50$

numiter $=5000$

phase1_on $=1$ 'this can be used as a switch to turn phase 1 on or off

Sheets("Input").Select

numworkers $=$ ActiveSheet.Cells $(1,2)$.Value

numskills $=$ ActiveSheet.Cells (2, 2). Value

numtasks $=$ ActiveSheet.Cells( 3,2$) \cdot$ Value

'initialize arrays

ReDim workerskill( $(0$ To numworkers $+1,0$ To numskills +1$)$ As Single

ReDim oworkerskill( $(0$ To numworkers $+1,0$ To numskills +1$)$ As Single

ReDim taskskill( $(0$ To numtasks $+1,0$ To numskills +1$)$ As Single

ReDim otaskskill( $(0$ To numtasks $+1,0$ To numskills +1$)$ As Single

ReDim tasktime (0 To numtasks +1$)$ As Single

ReDim otasktime(0 To numtasks +1$)$ As Single 
ReDim workercapacity $(0$ To numworkers +1$)$ As Single

ReDim oworkercapacity (0 To numworkers +1$)$ As Single

ReDim traincost $(0$ To numskills $+1,0$ To 5, 0 To 5) As Single

ReDim otraincost(0 To numskills $+1,0$ To 5, 0 To 5) As Single

ReDim traintime( 0 To numskills $+1,0$ To 5, 0 To 5) As Single

ReDim otraintime(0 To numskills $+1,0$ To 5, 0 To 5) As Single

ReDim workerassign $(0$ To numworkers +1 , 0 To numtasks +1$)$ As Single

ReDim bestworkerassign(0 To numworkers + 1, 0 To numtasks + 1) As Single

ReDim workertaskcost $(0$ To numworkers $+1,0$ To numtasks +1$)$ As Single

ReDim oworkertaskcost $(0$ To numworkers $+1,0$ To numtasks +1$)$ As Single

ReDim workertasktime $(0$ To numworkers $+1,0$ To numtasks +1$)$ As Single

ReDim oworkertasktime $(0$ To numworkers $+1,0$ To numtasks +1$)$ As Single

ReDim taskassigned(0 To numtasks +1$)$ As Single

ReDim tcost $(0$ To numskills $+1,0$ To 5) As Single

ReDim ttime $(0$ To numskills $+1,0$ To 5) As Single

ReDim available(0 To numworkers * numtasks $+1,0$ To 3) As Single

ReDim totaltaskcost (0 To numtasks +1$)$ As Single

ReDim totalworkercost (0 To numworkers +1$)$ As Single

ReDim workerphase1(0 To numworkers + 1) As Single

For $\mathrm{b}=0$ To numworkers +1

workercapacity $(b)=0$

oworkercapacity $(b)=0$

For $\mathrm{k}=0$ To numskills +1

workerskill $(\mathrm{b}, \mathrm{k})=0$

oworkerskill $(\mathrm{b}, \mathrm{k})=0$

Next k

Next b

For $\mathrm{b}=0$ To numworkers $*$ numtasks +1

For $\mathrm{k}=0$ To 3

available $(\mathrm{b}, \mathrm{k})=0$

Next k

Next b

For $\mathrm{b}=0$ To numtasks +1

$$
\begin{aligned}
& \text { tasktime }(\mathrm{b})=0 \\
& \text { otasktime }(\mathrm{b})=0 \\
& \text { taskassigned }(\mathrm{b})=0 \\
& \text { totaltaskcost }(\mathrm{b})=0 \\
& \text { For } \mathrm{k}=0 \text { To numskills }+1 \\
& \quad \text { taskskill }(\mathrm{b}, \mathrm{k})=0 \\
& \quad \text { otaskskill }(\mathrm{b}, \mathrm{k})=0
\end{aligned}
$$




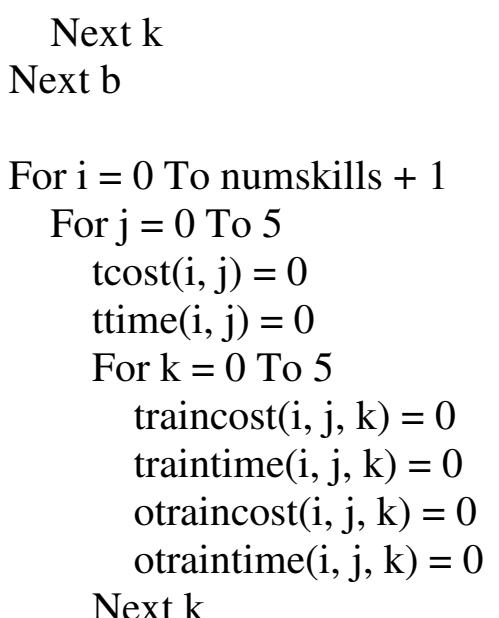

\section{Next j}

Next $\mathrm{i}$

For $\mathrm{b}=1$ To numworkers

totalworkercost $(b)=0$

For $\mathrm{k}=1$ To numtasks

$\operatorname{workerassign}(\mathrm{b}, \mathrm{k})=0$

workertaskcost $(\mathrm{b}, \mathrm{k})=0$

$\operatorname{oworkertask\operatorname {cost}}(\mathrm{b}, \mathrm{k})=0$

Next k

Next b

'read in data from file

For $b=1$ To numworkers

For $\mathrm{k}=1$ To numskills

$$
\text { oworkerskill }(\mathrm{b}, \mathrm{k})=\operatorname{ActiveSheet} \cdot \operatorname{Cells}(6+\mathrm{b}, 1+\mathrm{k})
$$

Next k

Next b

For $\mathrm{b}=1$ To numtasks

For $\mathrm{k}=1$ To numskills

otaskskill(b, k) = ActiveSheet.Cells $(6+$ numworkers $+3+\mathrm{b}, 1+\mathrm{k})$

Next k

Next b

For $b=1$ To numtasks

otasktime $(b)=$ ActiveSheet.Cells $(6+$ numworkers $+3+$ numtasks $+2+b, 2)$

Next b

For $\mathrm{b}=1$ To numworkers

oworkercapacity $(\mathrm{b})=$ ActiveSheet.Cells $(6+$ numworkers $+3+$ numtasks $+2+$ numtasks $+2+b, 2$ ) 
Next b

For $\mathrm{i}=1$ To numskills

For $\mathrm{j}=1$ To 5

$\operatorname{tcost}(\mathrm{i}, \mathrm{j})=$ ActiveSheet.Cells $(6+$ numworkers $+3+$ numtasks $+2+$ numtasks $+2+$ numworkers $+3+\mathrm{i}, 1+\mathrm{j}$ )

Next j

Next i

For $\mathrm{i}=1$ To numskills

For $\mathrm{j}=1$ To 5

ttime $(\mathrm{i}, \mathrm{j})=$ ActiveSheet.Cells $(6+$ numworkers $+3+$ numtasks $+2+$ numtasks +2

+ numworkers $+3+$ numskills $+3+\mathrm{i}, 1+\mathrm{j}$ )

Next $\mathrm{j}$

Next i

For $\mathrm{i}=1$ To numskills

For $\mathrm{j}=1$ To 5

For $\mathrm{k}=1$ To 5

If $\mathrm{j}<\mathrm{k}$ And $\mathrm{k}>1$ Then

$\operatorname{otraincost}(i, j, k)=\operatorname{otraincost}(i, j, k-1)+\operatorname{tcost}(i, k)$

End If

Next k

Next j

Next $\mathrm{i}$

For $\mathrm{i}=1$ To numskills

For $\mathrm{j}=1$ To 5

For $\mathrm{k}=1$ To 5

If $\mathrm{j}<\mathrm{k}$ And $\mathrm{k}>1$ Then

otraintime $(\mathrm{i}, \mathrm{j}, \mathrm{k})=$ otraintime $(\mathrm{i}, \mathrm{j}, \mathrm{k}-1)+\operatorname{ttime}(\mathrm{i}, \mathrm{k})$

End If

Next k

Next j

Next i

'find task cost and training time for each worker for each task

For $\mathrm{i}=1$ To numworkers

For $\mathrm{j}=1$ To numtasks

oworkertasktime $(i, j)=$ otasktime $(j)$

For $\mathrm{k}=1$ To numskills

If oworkerskill(i, k) < otaskskill(j, k) And otaskskill(j, k) > 1 Then

$\operatorname{oworkertaskcost}(i, j)=\operatorname{oworkertask\operatorname {cost}}(\mathrm{i}, \mathrm{j})+\operatorname{otraincost}(k$, oworkerskill $(i, k)$, otaskskill(j, k)) 
oworkertasktime $(i, j)=$ oworkertasktime $(i, j)+\operatorname{otraintime}(k$, oworkerskill $(i, k)$, otaskskill $(\mathrm{j}, \mathrm{k})$ )

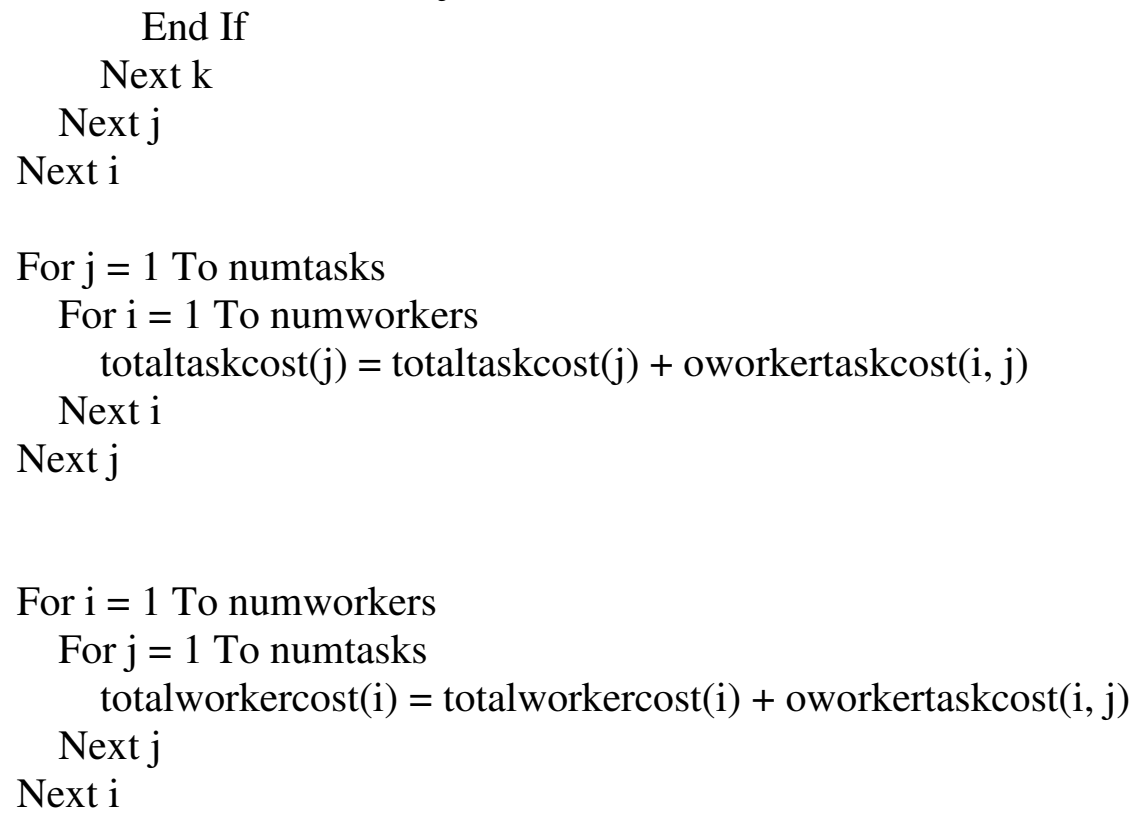

For $\mathrm{i}=1$ To numskills 


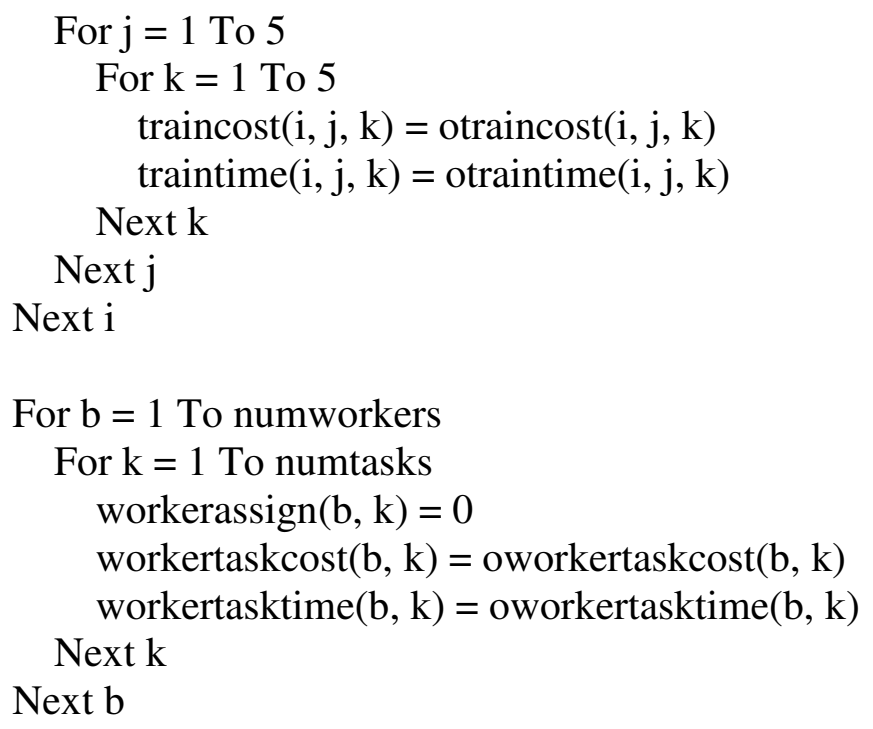

For $\mathrm{b}=1$ To numworkers

workerphase $1(b)=0$

Next b

totalcost $=0$

numtaskassigned $=0$

If phase1_on =1 Then 'this can be used as a switch to turn phase 1 on or off

'start phase 1 - each worker assigned 1 task

Do While numtaskassigned < numworkers

'find lowest skilled worker - worker with the highest totalcost

'make sure they are not already assigned

$\operatorname{maxcost}=0$

For $\mathrm{i}=1$ To numworkers

If workerphase $1(\mathrm{i})=0$ And totalworkercost $(\mathrm{i})>\operatorname{maxcost}$ Then

maxcost $=$ totalworkercost $(\mathrm{i})$

maxcostworker $=\mathrm{i}$

End If

Next i

'find lowest cost task for maxcost worker - make sure task not already assigned 'make sure worker has enough capacity

mincost $=99999999$

For $\mathrm{j}=1$ To numtasks

If taskassigned $(\mathrm{j})=0$ And workertasktime $(\operatorname{maxcostworker}, \mathrm{j})<=$ workercapacity(maxcostworker) And workertaskcost(maxcostworker, $\mathrm{j})<$ mincost Then

mincost $=$ workertaskcost $(\operatorname{maxcostworker}, \mathrm{j})$ 


\section{mincosttask $=\mathrm{j}$}

\section{End If}

\section{Next $j$}

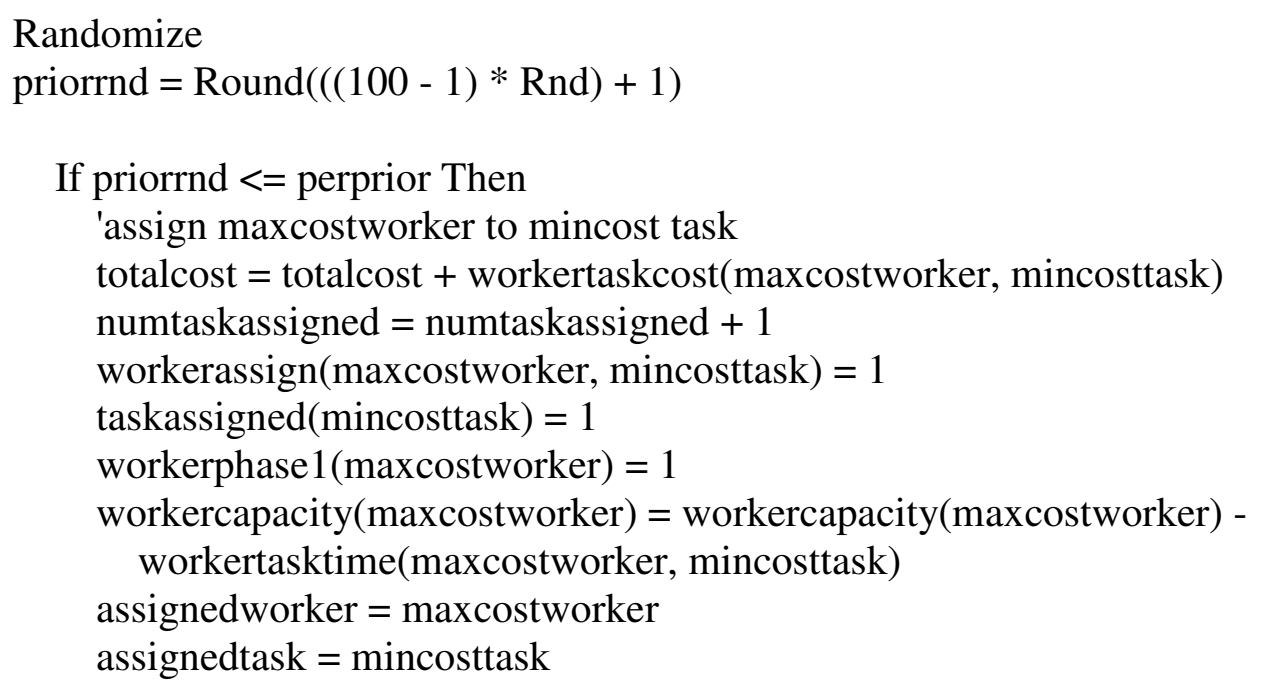

\section{End If}

\section{If priorrnd $>$ perprior Then}

'form available list and choose assigned task from available list

numonlist $=0$

For $\mathrm{j}=1$ To numtasks

If taskassigned $(\mathrm{j})=0$ And workertasktime $(\operatorname{maxcostworker}, \mathrm{j})<=$ workercapacity(maxcostworker) And

workertaskcost (maxcostworker, $\mathrm{j})<\operatorname{mincost} *(1+$ (perrestrict / 100)) Then

numonlist $=$ numonlist +1

available(numonlist, 1$)=$ maxcostworker

End If

available(numonlist, 2 ) $=\mathrm{j}$

\section{Next $\mathrm{j}$}

\section{Randomize}

restrictrnd $=\operatorname{Round}((($ numonlist -1$) *$ Rnd $)+1)$

assignedworker $=$ available $($ restrictrnd, 1$)$

assignedtask $=$ available $($ restrictrnd, 2$)$

totalcost $=$ totalcost + workertaskcost(assignedworker, assignedtask)

numtaskassigned $=$ numtaskassigned +1

workerassign(assignedworker, assignedtask) $=1$

taskassigned(assignedtask) $=1$

workerphase 1 (assignedworker $)=1$ 
workercapacity(assignedworker) = workercapacity(assignedworker) End If workertasktime(assignedworker, assignedtask)

'update workerskills for assignedworker based on training received for assignedtask

For $\mathrm{k}=1$ To numskills

If workerskill(assignedworker, $\mathrm{k}$ ) < taskskill(assignedtask, k) Then workerskill(assignedworker, $\mathrm{k}$ ) $=$ taskskill(assignedtask, $\mathrm{k}$ )

End If

Next k

'update workertaskcost and workertasktime for assignedworker For $\mathrm{j}=1$ To numtasks

If taskassigned $(\mathrm{j})=0$ Then

workertaskcost (assignedworker, $\mathrm{j})=0$

workertasktime (assignedworker, $\mathrm{j}$ ) = otasktime $(\mathrm{j})$

For $\mathrm{k}=1$ To numskills

If workerskill(assignedworker, k) < taskskill(j, k) And taskskill(j, k) > 1

Then

workertaskcost (assignedworker, $\mathbf{j})=$ workertaskcost $($ assignedworker, $\mathrm{j})+\operatorname{traincost}(\mathrm{k}$, workerskill(assignedworker, $\mathrm{k})$, taskskill $(\mathrm{j}, \mathrm{k})$ ) workertasktime (assignedworker, $\mathrm{j})=$ workertasktime(assignedworker, $\mathrm{j})+$ traintime $(\mathrm{k}$, workerskill(assignedworker, k), taskskill(j, k))

\section{End If}

Next k

End If

Next $j$

Loop

End If 'If phase1_on $=1$

'end of phase 1 switch

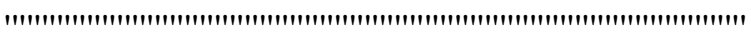

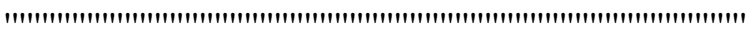

'start phase 2 - assign remaining tasks

Do While numtaskassigned < numtasks 'repeat until all tasks assigned

'find highest cost task - make sure it is not already assigned

maxcost $=-55$

For $\mathrm{j}=1$ To numtasks

If taskassigned $(j)=0$ And totaltaskcost $(j)>\operatorname{maxcost}$ Then 


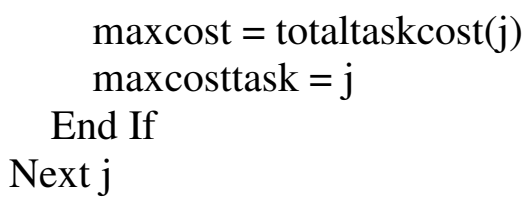

'find lowest cost worker for highest cost task - make sure worker has enough capacity

mincost $=9999999$

mincostworker $=0$

For $\mathrm{i}=1$ To numworkers

If workertasktime(i, maxcosttask) $<=$ workercapacity(i) And workertaskcost(i, maxcosttask) < mincost Then

mincost $=$ workertaskcost $(\mathrm{i}$, maxcosttask $)$

mincostworker $=\mathrm{i}$

End If

Next $i$

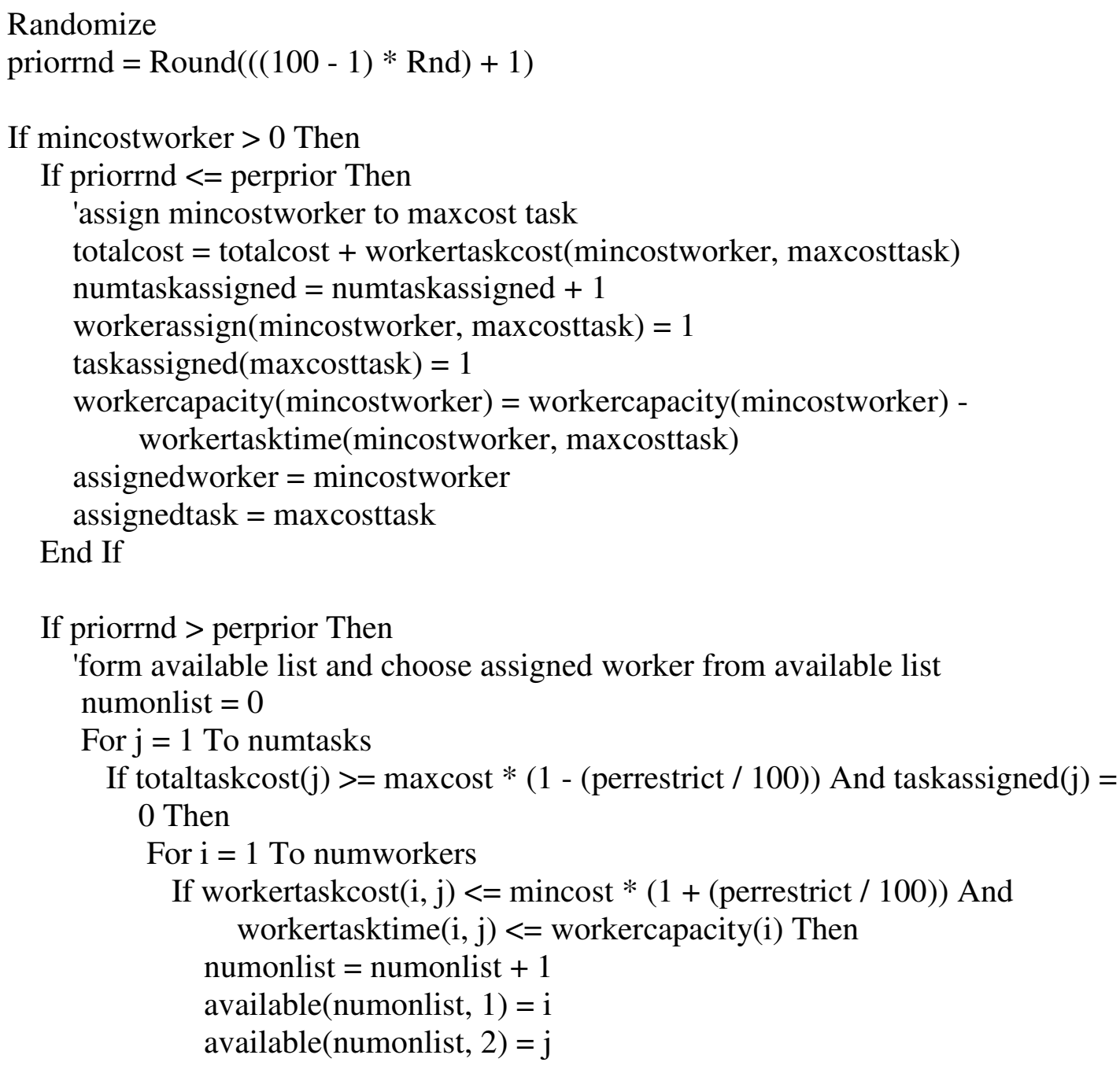




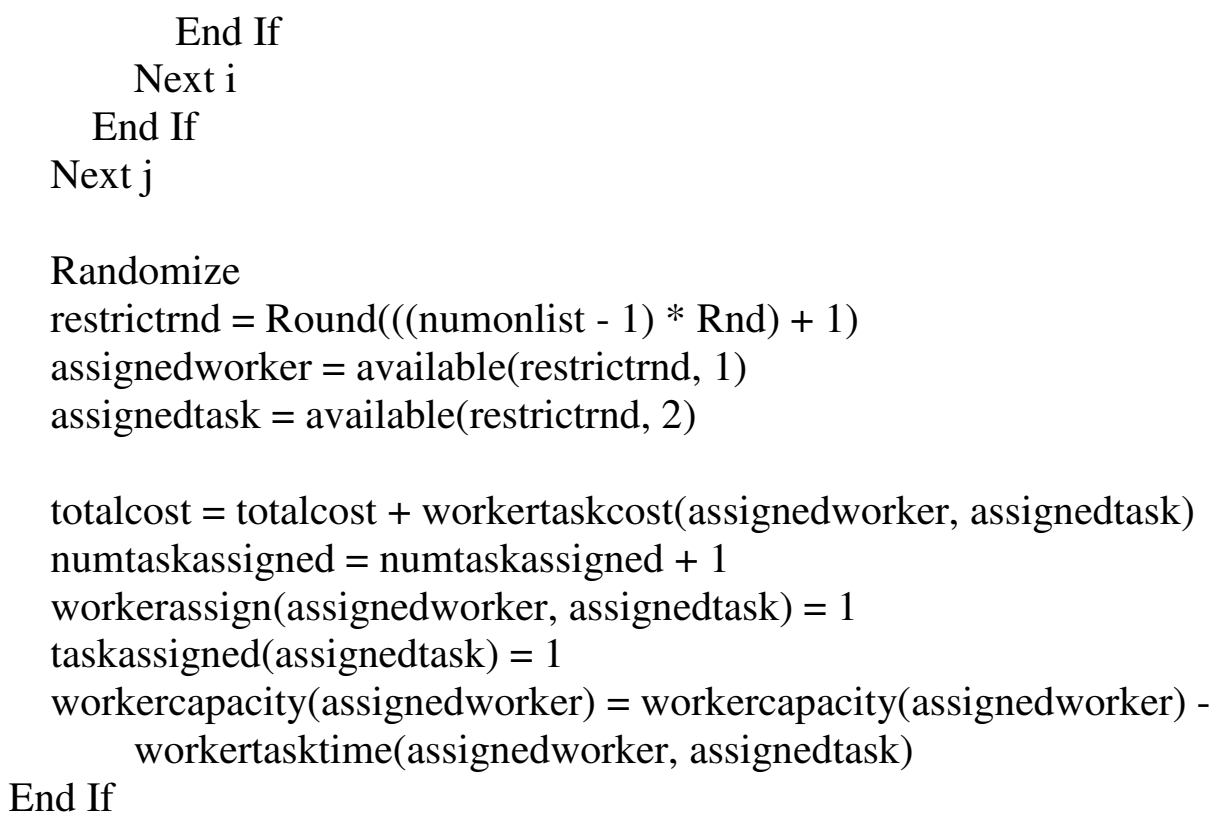

'update workerskills for assignedworker based on training received for assignedtask

For $\mathrm{k}=1$ To numskills

If workerskill(assignedworker, $\mathrm{k}$ ) < taskskill(assignedtask, k) Then

workerskill(assignedworker, $\mathrm{k}$ ) = taskskill(assignedtask, $\mathrm{k}$ )

\section{End If}

Next k

'update workertaskcost and workertasktime for assignedworker

For $\mathrm{j}=1$ To numtasks

If taskassigned $(j)=0$ Then

workertaskcost(assignedworker, $\mathrm{j}$ ) $=0$

workertasktime(assignedworker, $\mathrm{j}$ ) = otasktime $(\mathrm{j}$ )

For $\mathrm{k}=1$ To numskills

If workerskill(assignedworker, $\mathrm{k})<\operatorname{taskskill}(\mathrm{j}, \mathrm{k})$ And taskskill(j, k) $>1$

Then

workertaskcost (assignedworker, $\mathrm{j})=$ workertaskcost(assignedworker, $\mathrm{j}$ )

$+\operatorname{traincost}(\mathrm{k}$, workerskill(assignedworker, $\mathrm{k})$, taskskill $(\mathrm{j}, \mathrm{k})$ )

workertasktime (assignedworker, $\mathrm{j}$ ) = workertasktime (assignedworker, $\mathrm{j}$ )

+ traintime $(\mathrm{k}$, workerskill(assignedworker, $\mathrm{k})$, taskskill( $\mathrm{j}, \mathrm{k})$ )

\section{End If}

Next k

End If

Next $\mathrm{j}$

End If 


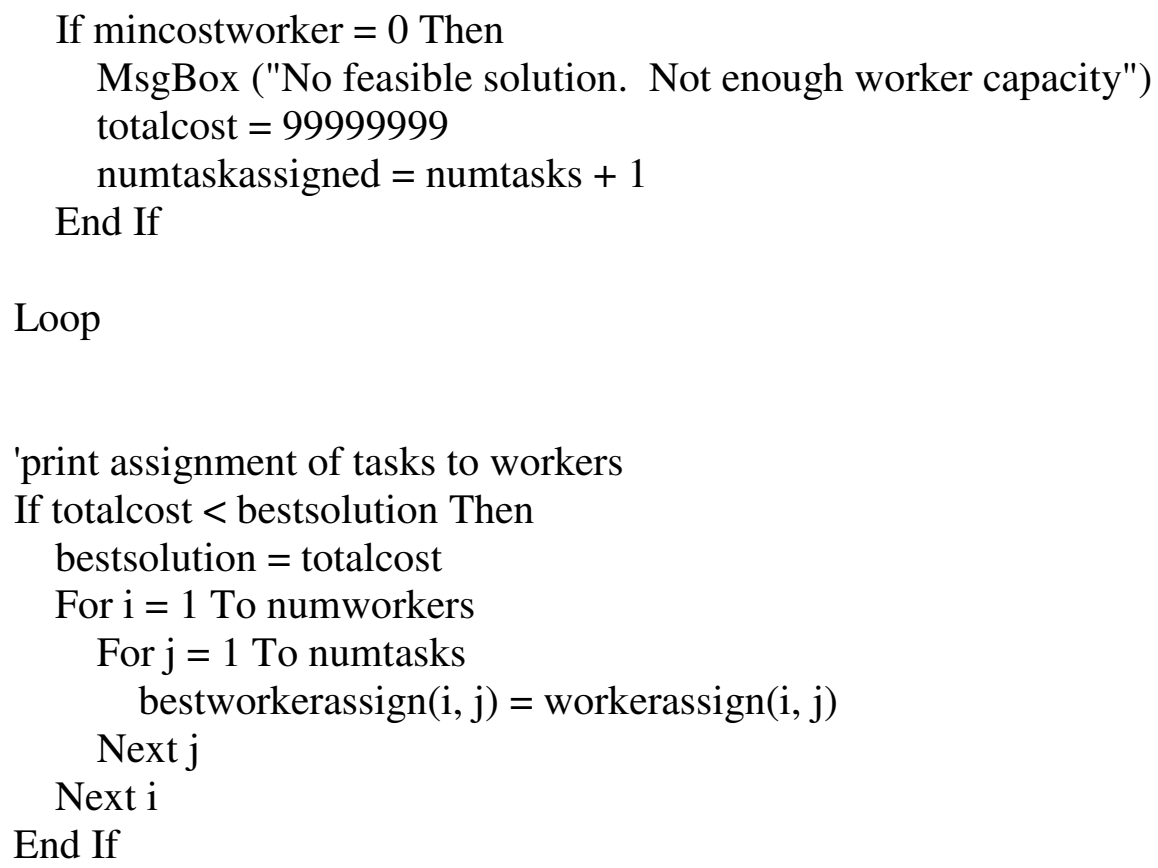

Next $r$

ActiveSheet.Cells $(1,1)=$ "\%Priority"

ActiveSheet.Cells $(1,2)=$ perprior

ActiveSheet.Cells $(2,1)=$ "\% Restriction"

ActiveSheet.Cells $(2,2)=$ perrestrict

ActiveSheet.Cells $(3,1)=$ "Number of Iterations"

ActiveSheet.Cells $(3,2)=$ numiter

ActiveSheet.Cells $(4,1)=$ "Best Solution Cost"

ActiveSheet.Cells $(4,2)=$ bestsolution

ActiveSheet.Cells $(6,1)=$ "Worker to Task Assignments"

ActiveSheet.Cells $(7,1)=$ "Worker"

ActiveSheet.Cells (7, 2) = "Task"

cellrow $=8$

For $\mathrm{i}=1$ To numworkers

For $\mathrm{j}=1$ To numtasks

If bestworkerassign $(i, j)=1$ Then

ActiveSheet.Cells(cellrow, 1) $=\mathrm{i}$

ActiveSheet.Cells (cellrow, 2$)=\mathrm{j}$

cellrow $=$ cellrow +1

End If

Next j

Next i

Sheets("Results").Select 


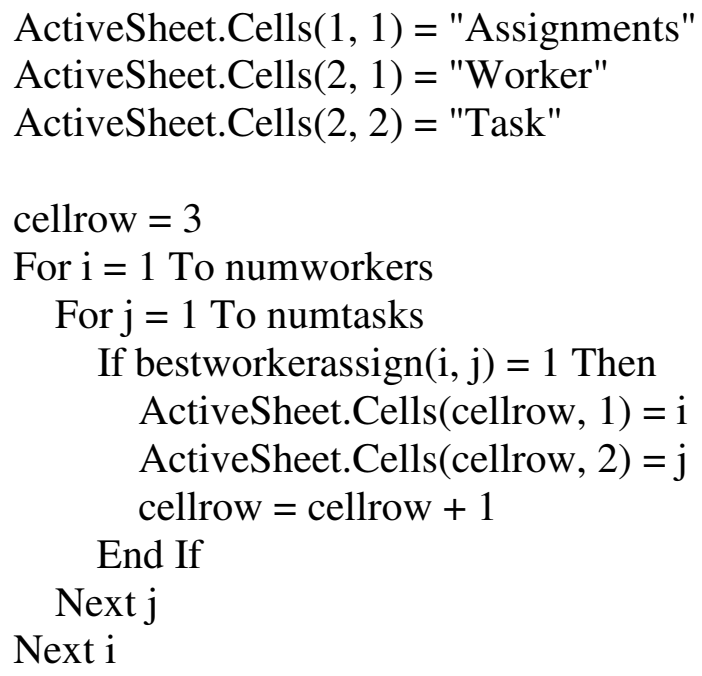

End Sub 


\section{APPENDIX G}

SCREENSHOTS OF RESULTS AND OUTPUT SHEETS

\begin{tabular}{|c|c|c|c|c|c|c|c|c|c|c|c|c|c|c|c|c|}
\hline & 096 & $f_{x}$ & & & & & & & & & & & & & & \\
\hline & A & B & C & D & $E$ & $\mathrm{~F}$ & G & $\mathrm{H}$ & 1 & $\mathrm{~J}$ & $\mathrm{~K}$ & $\mathrm{~L}$ & $M$ & $\mathrm{~N}$ & 0 & $\sqrt{\hat{\Lambda}}$ \\
\hline 1 & Assignments & & & $\begin{array}{l}\text { Training } \\
\text { Needs }\end{array}$ & & & & & & & & & & & & \\
\hline 2 & Worker & Task & & Worker & $\begin{array}{c}\text { Skill } \\
\text { Number }\end{array}$ & $\begin{array}{l}\text { Skill } \\
\text { Name }\end{array}$ & $\begin{array}{l}\text { From } \\
\text { Level }\end{array}$ & To Level & & & & & & & & \\
\hline 3 & 1 & 2 & & 1 & 5 & Skill 5 & 4 & 5 & & & & & & & & \\
\hline 4 & 2 & 6 & & 1 & 6 & Skill 6 & 1 & 5 & & & & & & & & \\
\hline 5 & 3 & 9 & & 1 & 11 & Skill 11 & 1 & 4 & & & & & & & & \\
\hline 6 & 4 & 3 & & 2 & 2 & Skill 2 & 2 & 4 & & & & & & & & \\
\hline 7 & 4 & 11 & & 2 & 3 & Skill 3 & 1 & 3 & & & & & & & & \\
\hline 8 & 5 & 12 & & 2 & 4 & Skill 4 & 3 & 4 & & & & & & & & \\
\hline 9 & 6 & 7 & & 2 & 7 & Skill 7 & 1 & 3 & & & & & & & & \\
\hline 10 & 7 & 4 & & 3 & 3 & Skill 3 & 3 & 4 & & & & & & & & $\equiv$ \\
\hline 11 & 7 & 5 & & 3 & 8 & Skill 8 & 1 & 3 & & & & & & & & \\
\hline 12 & 8 & 1 & & 3 & 11 & Skill 11 & 4 & 5 & & & & & & & & \\
\hline 13 & 8 & 8 & & 4 & 1 & Skill 1 & 1 & 2 & & & & & & & & \\
\hline 14 & 8 & 10 & & 4 & 2 & Skill 2 & 2 & 4 & & & & & & & & \\
\hline 15 & 9 & 13 & & 4 & 5 & Skill 5 & 1 & 4 & & & & & & & & \\
\hline 16 & 7 & 5 & & 4 & 6 & Skill 6 & 2 & 4 & & & & & & & & \\
\hline 17 & 8 & 1 & & 4 & 8 & Skill 8 & 2 & 4 & & & & & & & & \\
\hline 18 & 8 & 8 & & 4 & 10 & Skill 10 & 3 & 4 & & & & & & & & \\
\hline 19 & 8 & 10 & & 5 & 2 & Skill 2 & 2 & 3 & & & & & & & & \\
\hline 20 & 9 & 13 & & 5 & 5 & Skill 5 & 1 & 4 & & & & & & & & \\
\hline 21 & & & & 5 & 10 & Skill 10 & 4 & 5 & & & & & & & & \\
\hline 22 & & & & 6 & 3 & Skill 3 & 1 & 2 & & & & & & & & \\
\hline 23 & & & & 6 & 4 & Skill 4 & 2 & 5 & & & & & & & & \\
\hline 24 & & & & 6 & 7 & Skill 7 & 2 & 3 & & & & & & & & \\
\hline 25 & & & & 6 & 11 & Skill 11 & 3 & 5 & & & & & & & & \\
\hline 26 & & & & 7 & 1 & Skill 1 & 4 & 5 & & & & & & & & \\
\hline 27 & & & & 7 & 6 & Skill 6 & 4 & 5 & & & & & & & & \\
\hline 28 & & & & 7 & 8 & Skill 8 & 2 & 4 & & & & & & & & \\
\hline 29 & & & & 7 & 9 & Skill 9 & 1 & 2 & & & & & & & & \\
\hline 30 & & & & 8 & 1 & Skill 1 & 2 & 5 & & & & & & & & \\
\hline 31 & 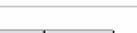 & & & 8 & 3 & Skill 3 & 2 & 5 & & & & & & & & $v$ \\
\hline 141 & - $M \backslash$ Input $\lambda R$ & Its & & & & & & & & & & & & & $>1$ & \\
\hline
\end{tabular}

The Results sheet reports the assignments and training needs associated with the

best solution. Each worker to task assignment is listed. The training for each skill is also listed for each worker. This sheet aids the company in determining which skills require training sessions. 


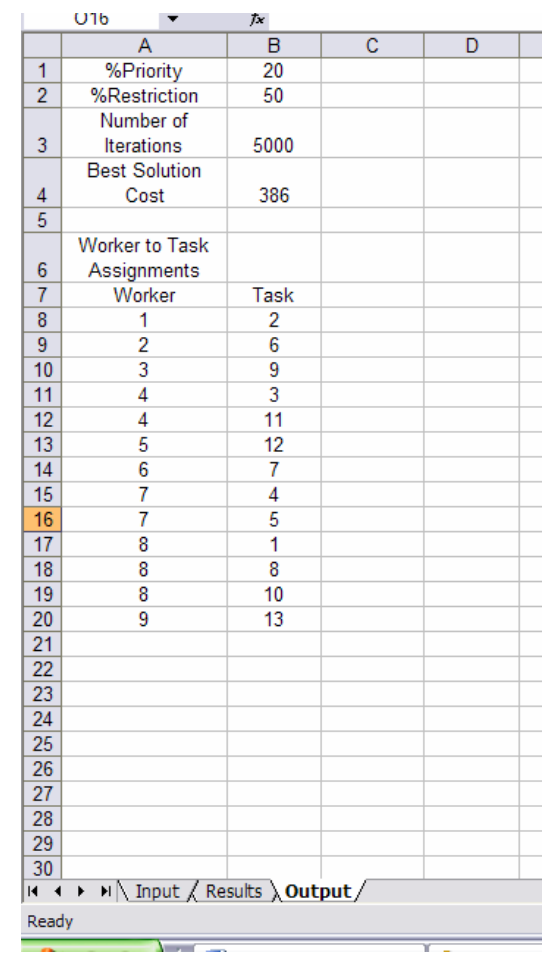

The Output sheet includes the percent priority and percent restriction values as well as the number of iterations. It also reports the best solution cost and assignments for the best solution. 


\section{VITA}

\section{Allison Michelle Douglas \\ amdoug01@louisville.edu}

\section{EDUCATION}

M.Eng. Industrial Engineering

August 2007

University of Louisville, Louisville, KY

B.S. Industrial Engineering

University of Louisville, Louisville, KY

August 2006

With High Honors

\section{HONORS AND AWARDS}

Provost-Hallmark Scholarship, University of Louisville

W.S. Speed Award, University of Louisville

2002 to present

Spring 2007

\section{EXTRACURRICULAR ACTIVITIES}

Speed School Student Council

Student Government Association

Institute of Industrial Engineers

Society of Women Engineers

Tau Beta Sigma Honorary Music Sorority

Society of Physics Students
Fall 2002 to present Summer 2003 to present Fall 2006 to present Fall 2006

Fall 2002 to Fall 2005 Fall 2002 to Fall 2003

\section{PERSONAL ACTIVITIES}

Big Brothers Big Sisters, Louisville, KY

$\mathrm{U}$ of L Marching Band, Pep Band and Community Band
2004 to present 2002-2005 